NASA/TM-2008-215275

\title{
Assessment of Current Jet Noise Prediction Capabilities
}

James E. Bridges and Abbas Khavaran

Glenn Research Center, Cleveland, Ohio

Craig A. Hunter

Langley Research Center, Hampton, Virginia 


\section{NASA STI Program . . . in Profile}

Since its founding, NASA has been dedicated to the advancement of aeronautics and space science. The NASA Scientific and Technical Information (STI) program plays a key part in helping NASA maintain this important role.

The NASA STI Program operates under the auspices of the Agency Chief Information Officer. It collects, organizes, provides for archiving, and disseminates NASA's STI. The NASA STI program provides access to the NASA Aeronautics and Space Database and its public interface, the NASA Technical Reports Server, thus providing one of the largest collections of aeronautical and space science STI in the world. Results are published in both non-NASA channels and by NASA in the NASA STI Report Series, which includes the following report types:

- TECHNICAL PUBLICATION. Reports of completed research or a major significant phase of research that present the results of NASA programs and include extensive data or theoretical analysis. Includes compilations of significant scientific and technical data and information deemed to be of continuing reference value. NASA counterpart of peer-reviewed formal professional papers but has less stringent limitations on manuscript length and extent of graphic presentations.

- TECHNICAL MEMORANDUM. Scientific and technical findings that are preliminary or of specialized interest, e.g., quick release reports, working papers, and bibliographies that contain minimal annotation. Does not contain extensive analysis.

- CONTRACTOR REPORT. Scientific and technical findings by NASA-sponsored contractors and grantees.

- CONFERENCE PUBLICATION. Collected papers from scientific and technical conferences, symposia, seminars, or other meetings sponsored or cosponsored by NASA.

- SPECIAL PUBLICATION. Scientific, technical, or historical information from NASA programs, projects, and missions, often concerned with subjects having substantial public interest.

- TECHNICAL TRANSLATION. Englishlanguage translations of foreign scientific and technical material pertinent to NASA's mission.

Specialized services also include creating custom thesauri, building customized databases, organizing and publishing research results.

For more information about the NASA STI program, see the following:

- Access the NASA STI program home page at http://www.sti.nasa.gov

- E-mail your question via the Internet to help@ sti.nasa.gov

- Fax your question to the NASA STI Help Desk at 301-621-0134

- Telephone the NASA STI Help Desk at 301-621-0390

- Write to: NASA Center for AeroSpace Information (CASI) 7115 Standard Drive Hanover, MD 21076-1320 
NASA/TM-2008-215275

AIAA-2008-2933

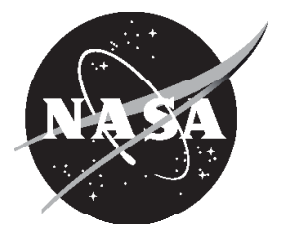

\section{Assessment of Current Jet Noise Prediction Capabilities}

James E. Bridges and Abbas Khavaran

Glenn Research Center, Cleveland, Ohio

Craig A. Hunter

Langley Research Center, Hampton, Virginia

Prepared for the

14th Aeroacoustics Conference

cosponsored by American Institute of Aeronautics and Astronautics (AIAA) and Council of European Aerospace Societies (CEAS)

Vancouver, British Columbia, Canada, May 5-7, 2008

National Aeronautics and

Space Administration

Glenn Research Center

Cleveland, Ohio 44135 
Trade names and trademarks are used in this report for identification only. Their usage does not constitute an official endorsement, either expressed or implied, by the National Aeronautics and Space Administration.

This work was sponsored by the Fundamental Aeronautics Program at the NASA Glenn Research Center.

Level of Review: This material has been technically reviewed by technical management.

Available from

NASA Center for Aerospace Information 7115 Standard Drive

Hanover, MD 21076-1320
National Technical Information Service 5285 Port Royal Road Springfield, VA 22161

Available electronically at http://gltrs.grc.nasa.gov 


\title{
Assessment of Current Jet Noise Prediction Capabilities
}

\author{
James E. Bridges and Abbas Khavaran \\ National Aeronautics and Space Administration \\ Glenn Research Center \\ Cleveland, Ohio 44135 \\ Craig A. Hunter \\ National Aeronautics and Space Administration \\ Langley Research Center \\ Hampton, Virginia 23681
}

\begin{abstract}
An assessment was made of the capability of jet noise prediction codes over a broad range of jet flows, with the objective of quantifying current capabilities and identifying areas requiring future research investment. Three separate codes in NASA's possession, representative of two classes of jet noise prediction codes, were evaluated, one empirical and two statistical. The empirical code is the Stone Jet Noise Module (ST2JET) contained within the ANOPP aircraft noise prediction code. It is well documented, and represents the state of the art in semi-empirical acoustic prediction codes where virtual sources are attributed to various aspects of noise generation in each jet. These sources, in combination, predict the spectral directivity of a jet plume. A total of 258 jet noise cases were examined on the ST2JET code, each run requiring only fractions of a second to complete. Two statistical jet noise prediction codes were also evaluated, JeNo v1, and Jet3D. Fewer cases were run for the statistical prediction methods because they require substantially more resources, typically a Reynolds-Averaged Navier-Stokes solution of the jet, volume integration of the source statistical models over the entire plume, and a numerical solution of the governing propagation equation within the jet. In the evaluation process, substantial justification of experimental datasets used in the evaluations was made. In the end, none of the current codes can predict jet noise within experimental uncertainty. The empirical code came within $2 \mathrm{~dB}$ on a $1 / 3$ octave spectral basis for a wide range of flows. The statistical code Jet3D was within experimental uncertainty at broadside angles for hot supersonic jets, but errors in peak frequency and amplitude put it out of experimental uncertainty at cooler, lower speed conditions. Jet3D did not predict changes in directivity in the downstream angles. The statistical code JeNo,v1 was within experimental uncertainty predicting noise from cold subsonic jets at all angles, but did not predict changes with heating of the jet and did not account for directivity changes at supersonic conditions. Shortcomings addressed here give direction for future work relevant to the statistical-based prediction methods. A full report will be released as a chapter in a NASA publication assessing the state of the art in aircraft noise prediction.
\end{abstract}

\section{Introduction}

Key to the engineering of quiet aircraft is the ability to calculate the noise that a given aircraft design will produce prior to building it. As in most areas of engineering science, engineers must optimize conflicting requirements and trades between competing goals can only be made if the engineer can predict the impact of the potential trades to the same fidelity in each discipline. The accuracy demands must also be balanced by the cost of the prediction. Early in a design cycle many configurations must be evaluated cheaply with relatively low accuracy, while later the calculations must become increasingly more accurate 
with higher fidelity as the design becomes finalized and as details become known. At all stages, it is important to know the limitations of the design tools being used, to know the uncertainty in the numbers being used in decision-making.

There is also a need to understand the accuracy and limitations of codes when you are in the business of developing prediction methods for engineering use. Scarce resources must be applied to where codes are most deficient and where these deficiencies hinder the engineering process. A rigorous program of assessing the prediction codes will clearly show the errors and uncertainties of the codes. Exercise of the prediction tools on demonstration design projects, especially projects aimed at developing and evaluating high-risk technologies, will illuminate where the errors most impact working engineers. This is the motivation for the current Fundamental Aeronautics Program at NASA, and the reason for the prediction assessment activities being undertaken within the various projects. A comprehensive assessment of prediction technologies for the acoustics discipline is being made across the projects. One chapter of this document will cover jet noise prediction methods. This paper is an overview of this activity and of this chapter.

The assessment starts by identifying families of test cases that are typical of jet noise problems, for which the codes are considered viable and yet stretch beyond the cases for which they were developed. Next, aeroacoustic theory and its embodiment in computer codes, both statistical and empirical, are described and their sensitivities to flow parameters are documented. Experimental data, both flow and noise, are obtained for these cases. Experimental uncertainty is established for the data using comparisons with other facilities. The prediction codes are exercised on the matrix of cases and results compared against the experimental data. These results have been compiled across the vast range of test cases and some in depth analysis done to understand the results and point to areas that require improvement.

\section{Jet Noise Case Taxonomy}

To parameterize the jet noise cases of interest, the following jet parameters were considered:

- Bypass Ratio (BPR)

- Mach number $\mathrm{M}=$ (ideally expanded jet velocity)/(local sound speed)

- Acoustic Mach number Ma = (ideally expanded jet velocity)/(ambient sound speed)

- Static Temperature Ratio $\left(\mathrm{T}_{\mathrm{s}, j} / \mathrm{T}_{\infty}\right)$

- Flight Mach number (Mf)

- Convergent/convergent-divergent nozzles (C/C-D)

- Internally/externally mixed nozzles (I/X)

- Azimuthal base periodicity $(\mathrm{m}=$ azimuthal Fourier mode)

With this chosen set of parameters, a taxonomy was established as given in Table 1. Essentially, the cases progress from single-stream jets $(B P R=0)$ to internally mixed nozzles with minimal bypass ratio, both subsonic and supersonic with convergent and convergent-divergent nozzles. Different internal splitters changed the bypass ratios from 0.1 to 1.0 and 2.0. At bypass ratios 5 and 8 the data were obtained from an internally mixed nozzle test with axisymmetric and lobed mixers, and from an externally mixed separate flow nozzle. At bypass ratio 11+ all the data were acquired at on externally mixed, separate flow nozzle systems with two different area ratios. Several of the jet conditions with externally mixed nozzle systems at BPR $=5$ and above have datasets with and without forward flight. 
Table 1 Taxonomy of test cases.

\begin{tabular}{|c|c|c|c|c|c|c|c|}
\hline Section & BPR & $\mathbf{M}=\mathbf{U}_{\mathrm{j}} / \mathbf{c}_{\mathrm{j}}$ & $\begin{array}{l}\text { Axial } \\
\text { Geometry }\end{array}$ & $\begin{array}{l}\text { Azimuthal } \\
\text { Geometry }\end{array}$ & $\mathbf{M a}=\mathbf{U}_{\mathrm{i}} / \mathbf{c}_{\infty}$ & $\mathbf{T}_{\mathrm{s}, \mathrm{j}} / \mathbf{T}_{\infty}$ & Data Source \\
\hline $\mathrm{A}$ & 0 & $0.5-1.0$ & Conv & $\mathrm{m}=0$ & $0.35-1.49$ & $0.85-2.7$ & $\begin{array}{l}\text { SHJAR, Tanna, } \\
\text { Viswanathan }\end{array}$ \\
\hline B & & $0.5-1.0$ & Conv & $\mathrm{m}=6$ & $0.5-1.49$ & $0.85-2.6$ & SHJARCHEV \\
\hline $\bar{C}$ & & $1.18-1.8$ & C-D & $\mathrm{m}=0$ & $1.0-2.4$ & $0.8-1.8$ & SHJAR, Tanna \\
\hline \multirow[t]{3}{*}{$\mathrm{D}$} & 0.1 & $0.5-1.0$ & internal, Conv & $\mathrm{m}=0$ & $0.5-1.3$ & $0.85-2.4$ & SDF07 \\
\hline & & $1.0-2.0$ & internal, Conv & $\mathrm{m}=0$ & $1.0-2.4$ & $0.8-1.8$ & SDF07 \\
\hline & & $1.0-2.0$ & internal, C-D & $\mathrm{m}=0$ & $1.0-2.4$ & $0.8-1.8$ & SDF07 \\
\hline \multirow[t]{3}{*}{$\mathrm{E}$} & 1 & $0.5-1.0$ & internal, Conv & $\mathrm{m}=0$ & $0.5-1.3$ & $0.85-2.4$ & SDF07 \\
\hline & & $1.0-2.0$ & internal, Conv & $\mathrm{m}=0$ & $1.0-2.4$ & $0.8-1.8$ & SDF07 \\
\hline & & $1.0-2.0$ & internal, C-D & $\mathrm{m}=0$ & $1.0-2.4$ & $0.8-1.8$ & SDF07 \\
\hline \multirow[t]{2}{*}{$\mathrm{F}$} & 2 & $0.5-1.0$ & internal, Conv & $\mathrm{m}=0$ & $0.5-1.3$ & $0.85-2.4$ & SDF07 \\
\hline & & $1.0-2.0$ & internal, Conv & $\mathrm{m}=0$ & $1.0-2.4$ & $0.8-1.8$ & SDF07 \\
\hline \multirow[t]{4}{*}{ G } & 5 & $<1$ & internal, Conv & $\mathrm{m}=0$ & $0.7-1.6$ & $2.5-3.0$ & LDIM05 \\
\hline & & $<1$ & & $\mathrm{~m}=8$ & $0.7-1.6$ & $2.5-3.0$ & LDIM05 \\
\hline & & $<1$ & & $\mathrm{~m}=20$ & $0.7-1.6$ & $2.5-3.0$ & LDIM05 \\
\hline & & $<1$ & external, Conv & $\mathrm{m}=0$ & $0.7-1.6$ & $2.5-3.0$ & HFXF07 \\
\hline \multirow[t]{4}{*}{$\mathrm{H}$} & 8 & $<1$ & internal, Conv & $\mathrm{m}=0$ & $0.6-1.2$ & $2.5-3.0$ & LDIM05 \\
\hline & & $<1$ & & $m=12$ & $0.6-1.2$ & $2.5-3.0$ & LDIM05 \\
\hline & & $<1$ & & $m=6$ & $0.6-1.2$ & $2.5-3.0$ & LDIM05 \\
\hline & & $<1$ & external, Conv & $\mathrm{m}=0$ & $0.6-1.2$ & $2.5-3.0$ & HFXF07 \\
\hline \multirow[t]{2}{*}{ I } & 11 & $<1$ & & $\mathrm{~m}=0$ & $0.5-1.1$ & $2.5-3.0$ & HFXF07 \\
\hline & 14 & $<1$ & & $\mathrm{~m}=0$ & $0.4-1.0$ & $2.5-3.0$ & HFXF07 \\
\hline
\end{tabular}

\section{Descriptions of Prediction Codes}

\section{Empirical Prediction Tools - Stone Jet Noise Module (ST2JET) within ANOPP}

The purpose of the NASA Aircraft Noise Prediction Program (ANOPP) is to predict noise from aircraft, accounting for the effects of the aircraft characteristics, its engines, its operations, and the atmosphere. The current jet noise module in ANOPP is ST2JET, based on the semi-empirical model developed by J. R. Stone of Modern Technologies Corporation. The method was developed from data with bypass ratios ranging from 0 (single stream) to 15 obtained from free jet facilities at NASA Glenn Research Center and NASA Langley Research Center as well as the anechoic free jet facilities at Lockheed and General Electric. The jet mixing noise and broadband shock noise components (associated with supersonic jets) also include corrections for forward flight effects.

Input decks for the ANOPP code were generated from the measured conditions of the experimental data. The full ANOPP Level25 code was used with only the ST2JET source module invoked.

\section{Statistical Prediction Tools-Jet3D}

Jet3D is based on a straightforward application of Lighthill's Acoustic Analogy (LAA) in three dimensions, shown solved and manipulated to give the far field mean-square acoustic pressure as a function of spatial observer position $\overrightarrow{\mathrm{x}}$ and time delay $\tau$ :

$$
\left\langle\mathrm{p}^{2}\right\rangle(\overrightarrow{\mathrm{x}}, \tau)=\frac{1}{16 \pi^{2} \mathrm{c}_{\infty}^{4}} \int_{\text {JET }} \int_{\mathrm{r}_{\mathrm{i}}} \hat{\mathrm{r}}_{\mathrm{j}} \hat{\mathrm{r}}_{\mathrm{m}} \hat{\mathrm{r}}_{\mathrm{n}} \int^{\infty} \mathrm{r}^{2} \frac{\partial^{4}}{\partial \tilde{\tau}^{4}}\left\langle\mathrm{~T}_{\mathrm{ij}} \mathrm{T}_{\mathrm{mn}}^{\prime}\right\rangle \mathrm{d} \vec{\zeta} \mathrm{d} \overrightarrow{\mathrm{z}}
$$

Here, $T_{i j}=\left(p-c_{\infty}^{2} \rho\right) \delta_{i j}-\sigma_{i j}+\rho u_{i} u_{j}$ is the Lighthill Stress Tensor, and quantities inside integrals are to be evaluated at a retarded time and corresponding position. By formulating the jet noise problem into an equivalent linear acoustics problem, LAA makes it possible to handle complex three-dimensional flows and arbitrary nozzle configurations with ease, thus making it a good choice for Propulsion Airframe 
Acoustics (PAA) applications. Compared to other methods based on acoustic propagation in a refractive medium or third-order convective wave equation formulation, LAA does not require intensive computations related to the propagation effect. The tradeoff, of course, is that LAA places a much heavier burden on source modeling, since the sources themselves produce analogous "propagation" effects through temporal and spatial phasing.

Turbulent velocity correlations are separated into space and time factors and modeled using the local one-point correlation (related to the Reynolds stress tensor) and a combination of Gaussian-type exponential functions and quadratic functions. The specific form of the correlation functions is not so important, as discussed in [1], as long as the spatial correlation function is integrable and the temporal correlation function is amenable to Fourier transforms. Generally, any reasonable correlation function can be used and calibrated to give good results, with the burden of noise prediction accuracy and correct spectrum shape falling on the CFD solution.

Thus, the Jet3D noise prediction algorithm is based on the volume integration over a set of equations giving the band-integrated mean-square acoustic pressure spectrum for the shear and self noise. The integration is carried out for each volume element in a discretized jet flow field using data obtained from a CFD solution. Within the integration routine, turbulent Reynolds stresses are computed using one of several linear or nonlinear anisotropic models[2], mean flow gradients are computed with a finite volume scheme, and local convection Mach number $\left(\mathrm{M}_{\mathrm{c}}\right)$ is modeled empirically using correlated data trends from the classic Davies experiment[3].

Jet3D is written in FORTRAN 77/90/95 with dynamic memory allocation, and is easily ported across numerous UNIX/Linux platforms. The main algorithms in Jet3D are vectorized to take advantage of compiler optimizations and vector processing on certain architectures. Jet3D also implements a low level multi-processing capability, where noise for multiple observers can be computed in parallel. Generally, noise predictions require on the order of 2-10 minutes per observer. In addition to a prediction mode, Jet3D can be run in one of several diagnostic modes to output noise source maps for follow-on analysis.

\section{Statistical Prediction Tools-JeNo,v1}

JeNo is also based on a form of the Acoustic Analogy, more akin to that of Lilley rather than Lighthill's formulation, where the effect of the mean flow has been removed from the source side of the equation. Particular attention has been paid to the variable selection in linearizing the set of Euler equations in order to derive acoustic equations that are strictly explicit. In this formulation, laid out in great detail in reference 4, several approximations have been suggested for the non-radiating base flow in order to conclude a single higher order acoustic equation for either pressure or density fluctuations. However, the set of equations governing the unsteady flow variables are self-contained, and with appropriate modeling of the non-linear components (which are recognized as the sources of aerodynamic noise), they should, in principle, determine the acoustic pressure. Approximations that lead to a single wave equation are strictly for computational benefits.

The acoustic equation solved by JeNo is a third-order convective wave equation. The operator part of the equation consists of non-uniformity in the mean velocity and temperature, and calculates the propagation filter or the Green's function for the acoustic radiation. The source side of the equation consists of non-linear terms that are the products of either fluctuating velocity/velocity, or velocity/temperature. For the purposes of this evaluation, it is noteworthy that the version of JeNo being exercised (version 1) has assumed isothermal flow; therefore terms involving unsteady temperature have been neglected, not because they are insignificant, but because current CFD capability of predicting temperature variance requires additional work. Another key element of the JeNo v1 is a non-compact source model.

Like Jet3D, JeNo requires statistical modeling for the two-point space-time correlation of velocities, and is more particular about the choice of the statistical functions that conform to measurement. Both methods require three fixed constants for the amplitude, time-scale, and length-scale in their source modeling. 
Statistical-based noise prediction models such as Jet3D or JeNo rely on RANS CFD solutions for their mean flow and turbulence information. Substantial effort has been placed on validating the CFD solutions against experimental data as part of the assessment exercise. Sensitivity in noise prediction as related to particular CFD code, or turbulence models within a single code has also been addressed.

While Jet3D uses a free-space Green's function, the propagation filter in JeNo is calculated numerically by solving the second-order compressible Rayleigh equation in a cylindrical coordinate system - therefore the Green's function is theoretically applicable to axisymmetric jets only. Most practical jets of interest are either axisymmetric, or become axisymmetric shortly after the exit. In principle, any deviation from axisymmetry produces azimuthal variation in the sound field. A threedimensional calculation of the Green's function is yet to be achieved successfully, and may require solving the set of linearized Euler equations in a rectangular coordinate system. For the purpose of the assessment exercise, a so-called 2-1/2D approximation has been implemented within JeNo, using either the line-of-sight or the line-of-source methods.

\section{Test Facilities and Instrumentation}

Single stream jet measurements were obtained primarily from the Small Hot Jet Acoustic Rig (SHJAR), located in the AeroAcoustic Propulsion Laboratory (AAPL) at the NASA Glenn Research Center in Cleveland, Ohio. As a jet noise testing rig, the SHJAR was designed to minimize rig noise sources, incorporating suggestions of Viswanathan[5] and Ahuja[6] to achieve this goal. The single flow jet rig uses $1 \mathrm{MPa}$ (150psi) air supplied by several remotely located compressors. The maximum mass flow rate is $2.5 \mathrm{~kg} / \mathrm{s}(6 \mathrm{lbm} / \mathrm{s})$ and the maximum temperature air is $1000 \mathrm{~K}\left(1320^{\circ} \mathrm{F}\right)$. The AAPL, which houses the SHJAR, is a $20 \mathrm{~m}(60-\mathrm{ft})$ radius geodesic dome lined with sound absorbing wedges which reduce sound reflection at all frequencies above $200 \mathrm{~Hz}$. The jet exhaust is directed outside through a large door. More information on the facility and the jet rig is found in Bridges \& Brown[7].

For dual stream test cases, data were acquired using the High Flow Jet Exit Rig (HFJER), which supplies air to the nozzle model at conditions similar to an aircraft engine. HFJER itself sits at the exit of the Nozzle Acoustic Test Rig (NATR), a 53-inch freejet that provides the forward flight airflow around the nozzle at speeds up to Mach 0.35. NATR in turn sits in the middle of the AeroAcoustic Propulsion Lab, mentioned above. Details of this facility can be found in reference [8].

\section{Instrumentation}

Turbulence data were acquired using Particle Image Velocimetry to validate CFD flow fields needed for input to the statistical prediction codes. Details of the systems used to acquire hot jet flow fields are contained in previously published papers $[9,10,11]$.

Far-field noise was measured using 24 Bruel \& Kjaer 1/4" microphones with Bruel \& Kjaer Nexus ${ }^{\mathrm{TM}}$ amplifiers, sampled by a DataMAX digital recorder at $200 \mathrm{kHz}$ for 8 seconds, simultaneously with all rig parameters. The microphones were located on an arc over 50 diameters from the nozzle exit over an angular range of $50^{\circ}$ to $165^{\circ}$. Microphone calibrations were maintained according to manufacturer's strict specifications.

\section{Determination of Experimental Uncertainty}

As a point of nomenclature, when determining the total experimental uncertainty, two source of uncertainty were considered: measurement uncertainty and facility dependence. The former can be determined by bookkeeping source of error in instrumentation and calibration procedures. The latter requires more effort, including direct comparisons of data from different, high-quality facilities.

\section{Measurement uncertainty in acoustic measurements}

Careful consideration of the instrumentation errors is critical to determining the experimental uncertainty band, needed for proper assessment of the prediction codes. Table 2 is a compilation of 
instrumentation errors and an analysis of how they contribute to the uncertainty of the far-field noise measurements used in the assessment.

Table 2 Estimation of Measurement Uncertainty

\begin{tabular}{|c|c|c|c|c|}
\hline Source & $\begin{array}{l}d B @ \text { low } \\
\text { freq }\end{array}$ & $\begin{array}{l}d B @ \\
\text { med freq }\end{array}$ & $\begin{array}{l}\text { dB @ } \\
\text { high freq }\end{array}$ & Comments \\
\hline atmos atten & 0.00001 & 0.001 & 0.1 & $1^{\circ} \mathrm{C}, 2 \% \mathrm{RH}->0.1 \mathrm{~dB}$ at $80 \mathrm{kHz}$ \\
\hline distance & 0.04 & 0.04 & 0.04 & 0.5 inch error in SHJAR (100inch) \\
\hline setpoint & 0.17 & 0.17 & 0.17 & $0.5 \%$ error in $\mathrm{Uj}$ \\
\hline pistonphone & 0.15 & 0.15 & 0.15 & B\&K 4220 spec \\
\hline $\begin{array}{l}\text { spectral } \\
\text { calibration }\end{array}$ & 0.27 & 0.17 & 0.27 & B\&K cal lab spec \\
\hline $\begin{array}{l}\text { 1/3 octave avg } \\
\text {-or- }\end{array}$ & 0.33 & 0.1 & 0.01 & chi-square analysis of $1 / 3$ octave integration at $90 \%$ confidence \\
\hline Narrowband avg & 0.61 & 0.61 & 0.61 & chi-square analysis of 150 averages at $90 \%$ confidence \\
\hline Total & $\begin{array}{l}0.96 \\
1.24 \\
\end{array}$ & $\begin{array}{l}0.73 \\
1.24\end{array}$ & $\begin{array}{l}0.74 \\
1.34\end{array}$ & $\begin{array}{l}1 / 3 \text { octave SPL }(\mathrm{dB}) \\
\text { Narrowband power spectral density }(\mathrm{dB})\end{array}$ \\
\hline
\end{tabular}

\section{Facility dependence of acoustic measurements}

The other source of uncertainty in experimental data is facility dependence. Details of the internal rig noise, anechoic chamber, free-jet size, aspiration and exhaust, and subtle differences in test procedure not captured in the measurement uncertainty above are sources of error [12]. Furthermore, there are significant differences in the noise produced by different nozzles that have the same basic geometric parameters, such as diameter. To estimate this source of uncertainty we compared results from the rigs used in the assessment with high quality published data, and in some cases with data acquired on the same nozzle at the NASA Langley Jet Noise Lab.

Figure 1 shows one such comparison for three cold flow conditions $(\mathrm{Ma}=0.5,0.7$. 0.9) and processed to remove all known facility differences such atmospheric conditions, microphone calibrations and microphone locations. Data from the facility comparison work of Viswanathan [13] are replotted in the figure along with the current dataset. The NASA SHJAR rig data lie between that of the other two rigs except at the highest frequencies where it dips below them both. We take the spread as an estimate of the experimental uncertainty, which is larger than the measurement uncertainty, especially at high frequencies.

Low speed, cold jets are challenging to measure primarily because the internal velocities are relatively high compared to the external jet velocity; internal rig noise will show up here where jet noise is very low. The other problem highlighted by Viswanathan [5] is one of scale, or Reynolds number independence. Smaller nozzles often have exit boundary layers that are not independent of Reynolds number, giving rise to high frequency noise sources that are anomalous. With heating, the Reynolds number becomes smaller for a given jet velocity, and the problem is exacerbated. Figure 2 shows how current data compare with published data for hot jets of different nozzle sizes. Not surprisingly, it agrees best with that of a similar size nozzle. The second plot in the figure, depicting detailed differences between the SHJAR third octave data and the published Boeing data, is another measure of the experimental uncertainty band in the jet noise data being used in this assessment.

In the interest of grounding current data against well-known datasets, Figure 3 and Figure 4 show onethird-octave spectra obtained on SHJAR against that of Tanna [14] at Ma $=0.5$ and 0.9 respectively at three different temperature ratios. Discrepancies are limited to high frequencies around $\mathrm{St}_{\mathrm{D}}=10$, where both possibly suffer from low Reynolds number effects, and at the peak frequencies of $90^{\circ}$, as was shown in Figure 1.

For dual-stream jets, experimental uncertainty and data validity were established by comparing against data acquired using the same nozzle hardware at the NASA Langley Jet Noise Lab. These comparisons confirmed our models of the internal rig noise for the dual stream rig, and data at those frequencies and angles were removed from the validation datasets. The comparisons also supported the estimate of rig-torig spectral variability to be between 1 and $2 \mathrm{~dB}$ for all observer angles. 


\section{Uncertainty in jet flow field statistics}

Because the statistical jet noise prediction codes relied on CFD input of mean and turbulent quantities, experimental data from several Particle Image Velocimetry (PIV) tests were used to ascertain the error in this input stream. Figure 5 shows a typical dataset consisting of two or three component measurements of mean and mean square velocity statistics over the first 20 or so jet diameters. The measurements of mean and mean square velocity have previously been validated against other datasets [9]; an example is given in Figure 6. These studies showed that turbulent velocity statistics, such as rms of velocity, from the first 1-2 jet diameters was not correct due to the small shear layer. Excluding data from the first two diameters, the mean velocities were within $1 \%$ of other, conventional measurements, and the rms values were within $5 \%$. This was sufficiently accurate to estimate the errors in the mean velocities and turbulent kinetic energy of the CFD solutions used as input to the statistical prediction codes.

\section{Uncertainty in CFD input to Statistical codes}

A detailed evaluation of three different turbulence models available within the NASA RANS code "Wind", namely the standard Chien $k-\varepsilon$ model, Mentor shear stress model (SST), and a variable diffusion model, was made by Georgiadis et al.[15]. There were significant differences in the mean centerline decay rate, and turbulent kinetic energy predicted by the different turbulence models varied by as much $40 \%$. When two of the flow solutions with variations of $10 \%$ in turbulent kinetic energy were used on a low Mach number, cold jet, the error in noise prediction caused by the variation in the flow input was determined to be less than $1 \mathrm{~dB}$, as seen in Figure 8

\section{Results}

\section{Data presentation}

In the assessment of prediction codes, the primary metric used was the $1 / 3$ octave SPL spectra at angles of $90^{\circ}$ and $150^{\circ}$ relative to the inlet axis. The effect of atmospheric attenuation was removed from the data, the data were transformed to an arc of radius 100 jet diameters, and normalized to Strouhal number scaling. In addition to the spectral shape, the ability to predict the overall sound pressure level (OASPL) over all angles may be considered as a measure to predict the strong directivity of jet noise, and so the OASPL vs polar angle and its deviation from experimental data were also computed for each case. As a summarizing metric, the average and variance in the OASPL difference was calculated; the average difference gives a measure of how well the prediction code calculates overall sound power over the range of jet conditions, and the variance measures how well the code predicts directivity.

\section{Empirical prediction code--ANOPP}

For brevity, only a smattering of detailed spectral directivity results will be shown in this paper. First, consider Figure 9, showing a plot of 1/3 octave SPL at two polar angles measured from the upstream axis. In the figure are data and ANOPP predictions for a single, $\mathrm{Ma}=0.5$ cold jet. To better quantify the error in the prediction relative to experimental uncertainty, the difference between data and prediction has been calculated and plotted in the righthand plot, along with two curves that indicate the uncertainty band associated with measurement error. In this example, the difference between prediction and data exceeds the uncertainty by several $\mathrm{dB}$, especially near the peak frequency and at higher frequencies at $150^{\circ}$. At $90^{\circ}$ the difference only slightly exceeds the uncertainty of the measurement.

Agreement between ANOPP prediction and data remains consistent when the jet flow is heated, as typified in the subsonic single flow hot jet shown in Figure 10. Likewise, for shock-free jets, such as the ideally expanded isothermal $\mathrm{M}=1.8$ case presented in Figure 11, the ANOPP prediction of jet noise is very close to the experimental uncertainty. When the jet has dual streams, such as a separate flow nozzle operating with a hot core flow and cool fan stream as given in Figure 12, the agreement is also nearly within experimental uncertainty. 
ANOPP's ability to predict jet noise from non-axisymmetric configurations was evaluated by applying it to a single-flow nozzle with somewhat aggressive chevrons. ANOPP has a parameter, the wetted perimeter, which is intended to capture the impact of such nozzle features. This was developed for chevrons on core nozzle of separate flow nozzles. When applied to external shear layer chevrons, as done in Figure 13, the results are disastrous. The predicted suppression of low frequencies is off by $10 \mathrm{~dB}$ or more.

A common element in many of the cases is a high frequency hump that is not found in the data. Using the jet noise component controls for the ST2Jet module, the various model sources are turned on and off to discern the cause of this high frequency hump within the code. The three main components for a shockfree jet are OUTSTRM, INSTRM, and MERGSTRM, intended to model the noise from the highest frequency initial (outer stream) shear layer, the intermediate-frequency (inner stream) shear layer, and the low-frequency (fully merged) jet respectively. These components are shown separately in Figure 14 . Note that in this example we are applying ANOPP to a single-stream jet, e.g. the parameter STREAM set to 1, indicating a single stream jet. The high frequency hump at Strouhal $=10$ is caused by the OUTSTRM source component, intended to capture the high frequency noise from the initial portion of the outer shear layer.

Figure 15 presents the OASPL directivity and error in predicting OASPL for the Ma $=0.5$, cold flow case using ANOPP. Here, thanks to summation over one-third octave bands, the prediction is within the uncertainty band except for the peak angle, where it overpredicts the OASPL.

To summarize the ability of the empirical code to predict jet flows from a wide array of situations (see Table 1) the OASPL error data were further processed to compute the average $\mu$ and rms $\sigma$ of the OASPL error over all $\mathrm{N}$ angles.

$$
\begin{aligned}
& \mu=\frac{1}{N} \sum_{N}\left(O A S P L_{A N O P P}-O A S P L_{E x p}\right) \\
& \sigma=\sqrt{\frac{1}{N}\left[\sum_{N}\left(O A S P L_{A N O P P}-O A S P L_{E x p}\right)-\mu\right]^{2}}
\end{aligned}
$$

Figure 16 presents the mean error in ANOPP-predicted OASPL for each of the 258 cases studied while Figure 17 presents the deviation in error across the polar angles for all the cases. The table of conditions for these cases, not shown here, proceeds roughly in the order of Table 1, with the different sections A-I given in the Table differentiated in the plot. Of note is the very poor result for cases in section $\mathrm{B}$, which were single-flow jets with chevrons. The capability of ANOPP to predict the effect of chevrons clearly is limited to applications on core streams of separate flow nozzle systems, not on outer nozzles. Otherwise, the error in ANOPP is seen to be fairly uniform across a wide array of jet flows, in keeping with its utility as a low-fidelity tool for systems analysis.

\section{Statistical prediction code--Jet3D}

A subset of jet cases were used in the assessment of statistical prediction codes, primarily single jet cases. When applied to the $\mathrm{Ma}=0.5$, cold jet case, Jet3D does not fare well, as shown in Figure 18. Spectral errors exceed $6 \mathrm{~dB}$ at $90^{\circ}$ near the peak of the spectrum. Errors are greater for the $130^{\circ}$ angle. The agreement was comparable for all the subsonic flow cases assessed. With heating, the error was somewhat less in spectral amplitude, although the peak frequency was off by a factor of 3-5 or more, as demonstrated in Figure 19, a comparison made at $\mathrm{Ma}=0.9, \mathrm{~T}_{\mathrm{s}, \mathrm{j}} / \mathrm{T}_{\infty}=2.7$. When compared on a fully expanded supersonic hot jet, the agreement at $90^{\circ}$ was much better. This case, a $M=1.4, T_{s, j} / T_{\infty}=2.2$ jet shown in Figure 20, was the case for which the Jet3D code was first developed. The code does not, however, capture the directivity, underpredicting the noise at the downstream angle of $150^{\circ}$ in both amplitude and peak frequency.

Of the cases examined with the Jet3D statistical jet noise code, spanning subsonic cold and hot jets and fully expanded hot supersonic jets, Jet3D is within experimental uncertainty only for the high 
temperature, high speed case at the observer angle of $90^{\circ}$. There are substantial discrepancies, both in amplitude and peak frequency, for all other flow cases and observer angles.

\section{Statistical prediction code--JeNo,v1}

A similar set of plots, this time using the statistical code JeNo,v1, is given in Figure 21. Here the prediction is within the experimental uncertainty at $90^{\circ}$ except at the highest frequencies. At $130^{\circ}$ the predictions lie right on the edge of the uncertainty band, but could be said to fall within the experimental uncertainty. This level of agreement, near or within the experimental uncertainty for all angles, was found to hold for all subsonic cold jets. With the addition of heat, the agreement begins to fail, particularly at aft angles as seen in Figure 22 where the peak amplitude of the spectra is underpredicted by $10 \mathrm{~dB}$ at $140^{\circ}$ and peak frequency underpredicted by a factor of 2 . The peak amplitude at $90^{\circ}$ is underpredicted by $4 \mathrm{~dB}$, with a mismatch in the frequency. Increasing the jet velocity, predictions were made on a fully expanded cold supersonic jet of $\mathrm{M}=1.8$ as shown in Figure 23. Here the amplitudes are predicted within 2dB, although the peak frequency at $130^{\circ}$ to the upstream axis is off by a factor of 4 .

Of the cases examined with the JeNo,v1 statistical jet noise code, spanning subsonic cold and hot jets and fully expanded code supersonic jets, JeNo is within experimental uncertainty at all angles for cold subsonic jets. JeNo,v1 fails to account for the addition of heat, especially at large angles to the upstream axis. Supersonic jets up to $\mathrm{M}=1.8$ are only predicted near to experimental uncertainty for $90^{\circ}$, being approximately correct in amplitude at large angles, but with a factor of 2 error in peak frequency.

\section{Discussion}

The real value in statistical prediction codes is not in their superiority in predicting the absolute spectral directivity of a round jet. The parametric variations of round jets can be culled to a limited number of cases and an empirical code made to capture the salient physics across the parametric space. This is the role of empirical codes, such as ANOPP, and to within the quality of the data used in their construction they do a very good job at predicting the noise of round jets. The true utility of statistical prediction codes is in their ability to predict the impact of geometric variations whose impact on the flow can be captured by a Reynolds-averaged Navier-Stokes solver. To that end, several cases of non-axisymmetric jets were explored using the JeNo code to assess its accuracy in predicting the change in noise relative to a comparable round jet.

The ability of statistical codes to accurately handle non-axisymmetric nozzle configurations depends upon the azimuthal order of the noise field. Since a full three-dimensional Green's function solver does not presently exist for the JeNo, one of two approximations must be made, a 'line of sight' assumption, or a 'line of source' assumption. The first assumes that the propagation of sound within the jet in a given azimuthal direction is constant for all azimuthal variations in source, leading to a prediction that varies with azimuthal angle. The second assumes that the far field is an average of all azimuthal variations in both source and propagation. This leads to an axisymmetric sound field. Jet flow fields with azimuthal modes below order 2 are capable of non-axisymmetric sound fields and should be handled by the line of sight approximation. Above this azimuthal mode, the noise field produced is statistically axisymmetric, making the line of source approximation more appropriate.

As an example of a low azimuthal mode jet, dual flow jets with an offset core stream was explored. The JeNo,v1 code was assessed to see if it could pick up the azimuthal variation produced.

Figure 24 shows the spectral directivity on the near and far sides of a wedge diverter placed in the fan stream of a separate flow nozzle. Predictions and data are shown for an axisymmetric nozzle at the same flow conditions as well. JeNo predicted the increase in noise at $90^{\circ}$ above $1 \mathrm{kHz}$ and the axisymmetry of the noise at broadside angles. It also predicted a strong increase in noise at high frequencies for the side toward the wedge, an effect found in the experimental data.

As this example demonstrates, while the statistical method still require further refinement and development, it bears the promise of predicting the impact of noise reduction concepts. 


\section{Conclusions}

Jet noise prediction codes currently in practice fall into two categories, empirical and statistical. Examples of both were evaluated over a broad range of round and nearly round jet flows against validated datasets. The empirical prediction code, ANOPP, was found to have a margin of error in OASPL of roughly $2 \mathrm{~dB}$ for most of the conditions investigated. Of the two statistical codes, JeNo,v1 was found to be very accurate, nearly within experimental uncertainty, for subsonic cold jets, but was clearly missing the mark for hot jets at all angles, and for supersonic jets at far aft angles. The other statistical code, Jet3D, adequately predicted jet noise spectra for hot supersonic jets for broadside observers, but had large discrepancies at subsonic conditions, requiring more investigation.

\section{Figures}

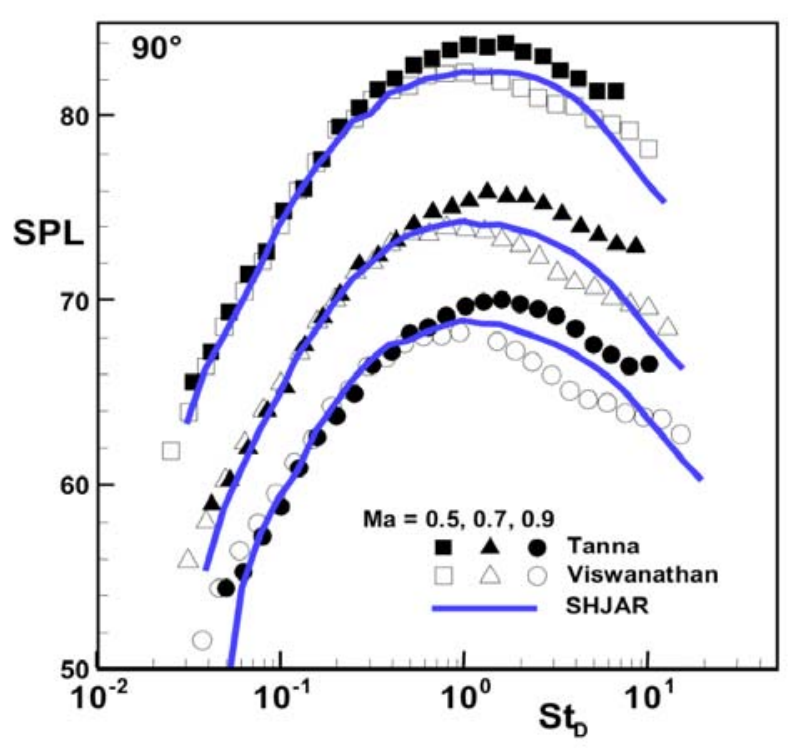

Figure 1 Comparison of SPL at $90^{\circ}$ for different jet speeds, Ma=0.5, 0.7, 0.9: current data (SHJAR), Tanna (1977) and of Viswanathan (2004). Figure from Viswanathan[5].
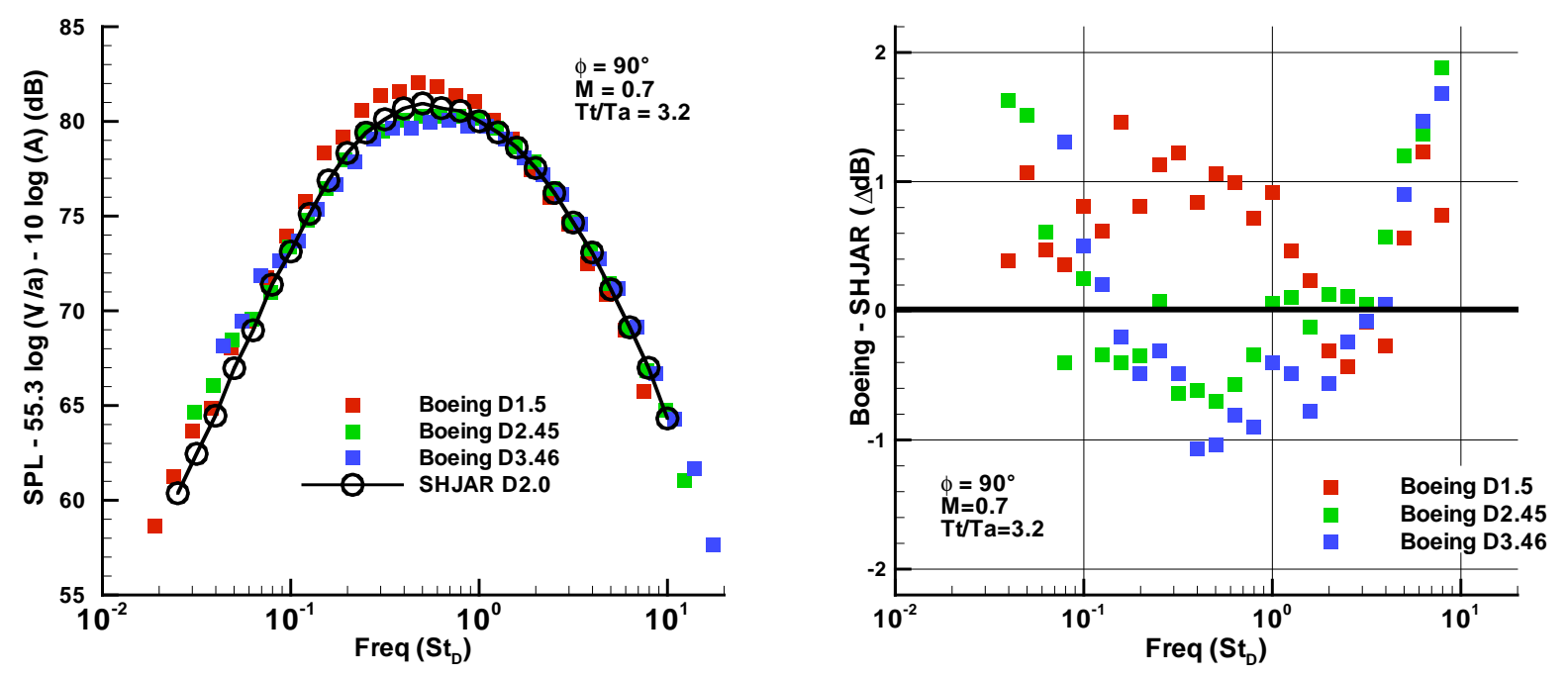

Figure 2 Comparison of hot jet SPL for different nozzle diameters, current data (SHJAR) and Vishwanathan (2005). Spectra acquired at $90^{\circ} M=0.7$, Total temperature ratio $=3.2$, normalized to standard day at 15 feet. 

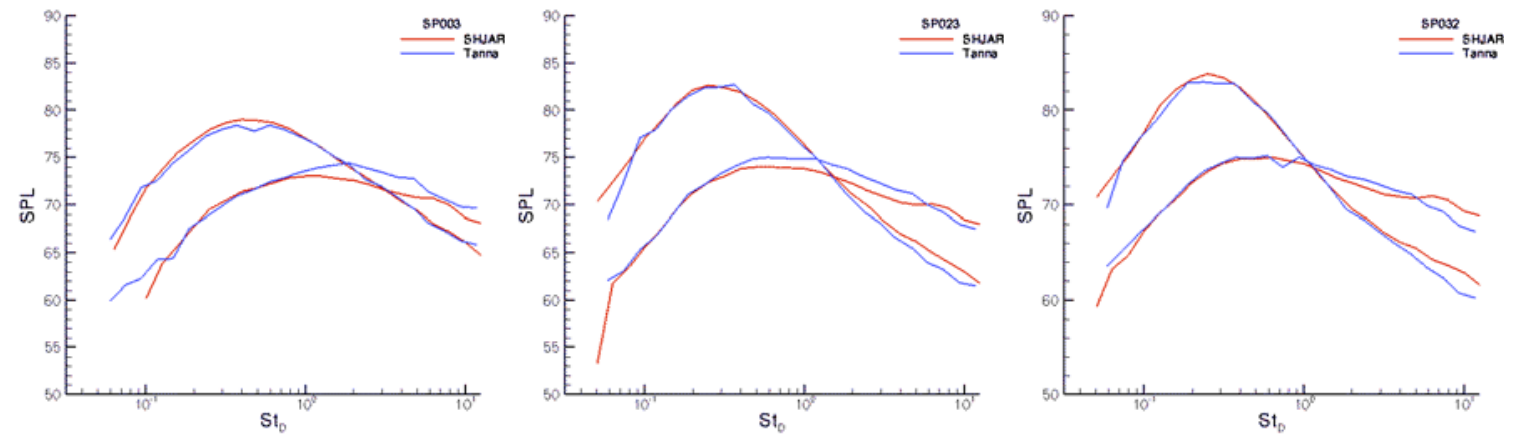

Figure 3 Comparison of SPL between SHJAR and Tanna (1977), Ma=0.5 for three static temperature ratios: (a) 0.86 (cold), (b) 1.76, (c) 2.27. Each pane shows spectra at $90^{\circ}$ (lower curve) and $150^{\circ}$ (upper curve).
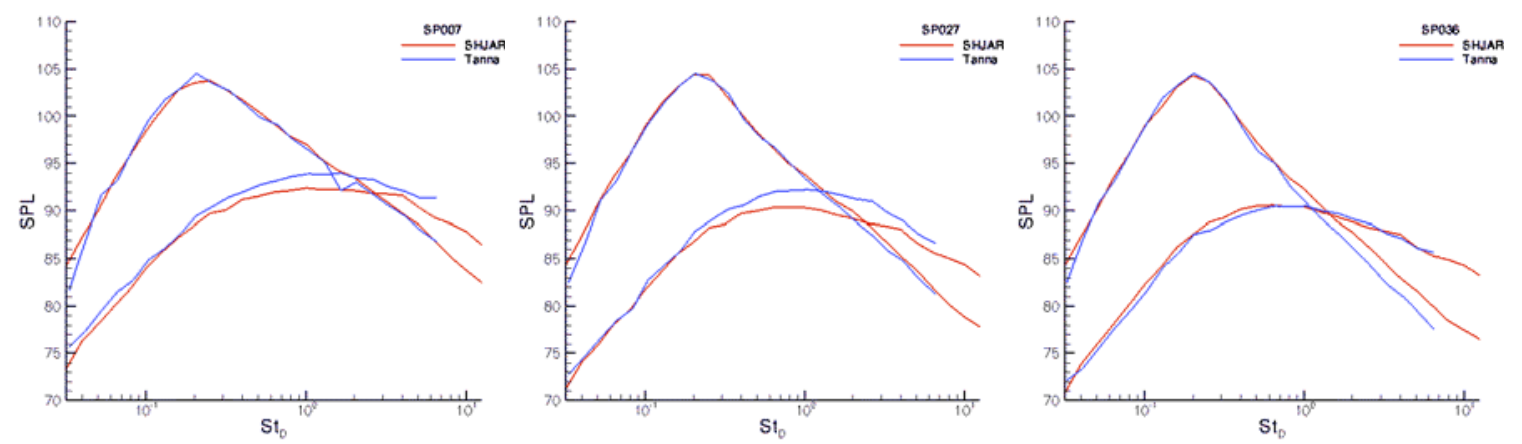

Figure 4 Comparison of SPL between SHJAR and Tanna (1977), Ma=0.9 for three static temperature ratios: (a) 0.86 (cold), (b) 1.76, (c) 2.27. Each pane shows spectra at $90^{\circ}$ (lower curve) and $150^{\circ}$ (upper curve).

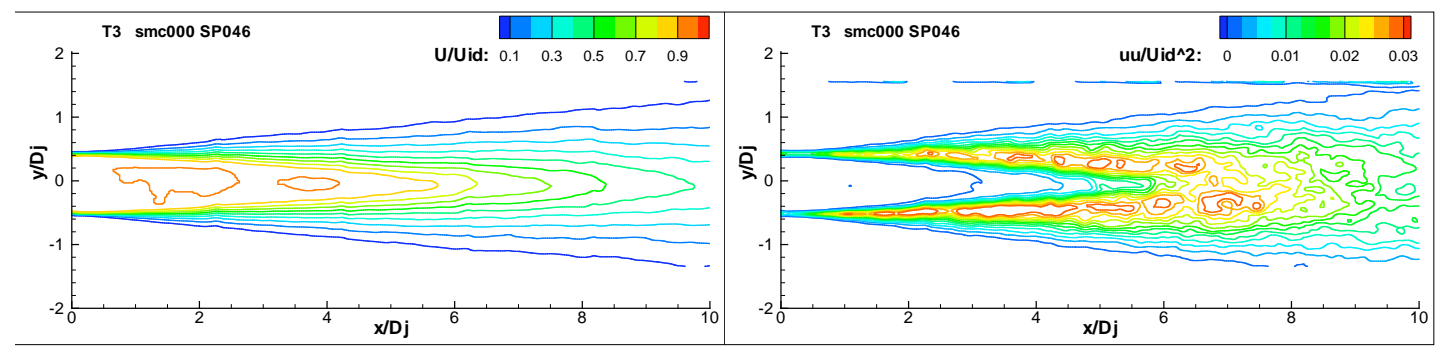

Figure 5 Typical flow field data provided by PIV for validating RANS CFD solutions being used as input to statistical noise prediction codes. 


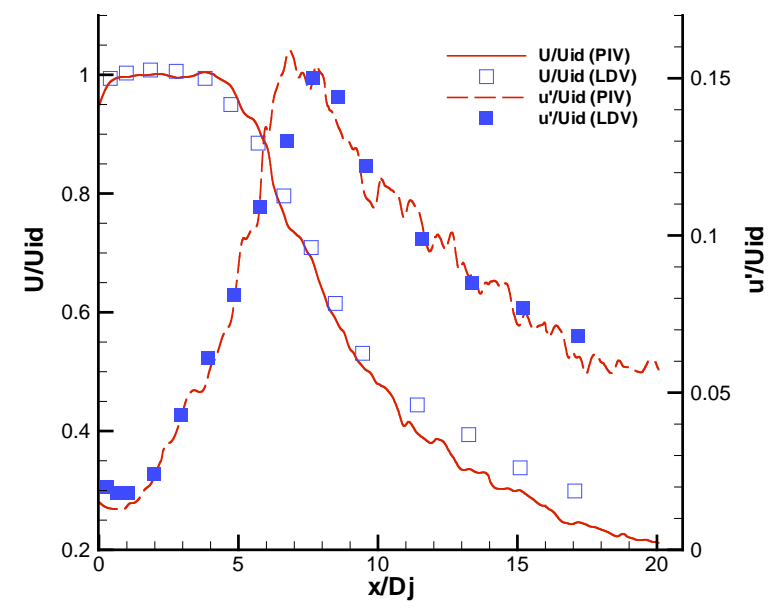

Figure 6 Comparison of PIV data used in assessment and LDV data of Lepicovsky. Ma $=0.9, T_{s, j} / T_{\infty}=$ 2.7; $y / D=0$ (centerline).

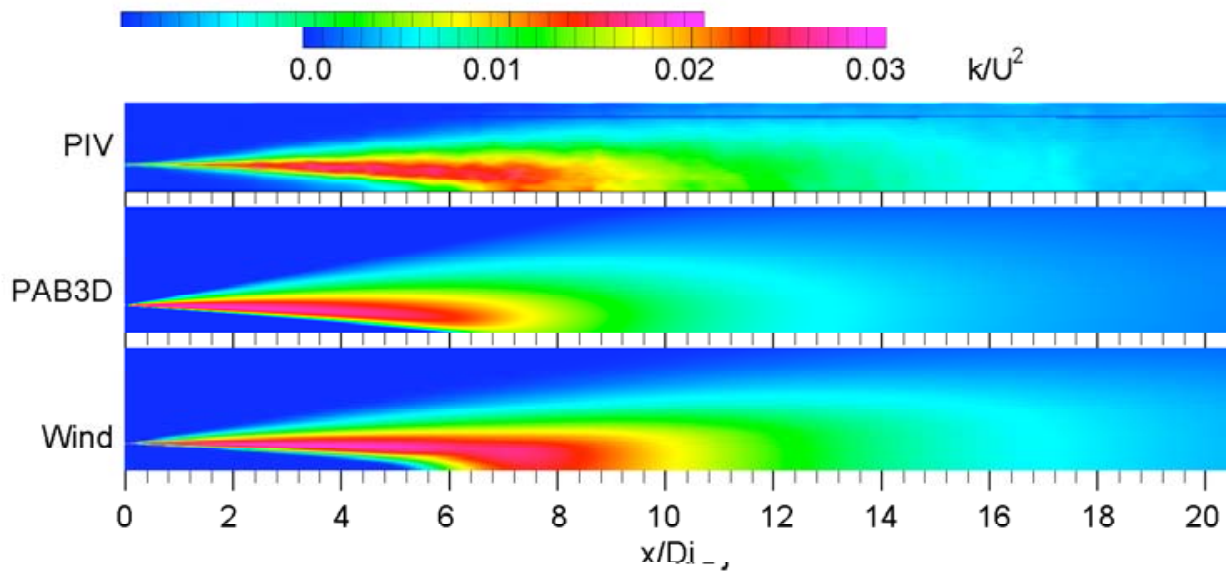

Figure 7 Comparisons of turbulent kinetic energy predictions from PAB3D and Wind codes with PIV data for $M a=0.5, T_{s, j} / T_{\infty}=1.67$ single stream jet flow.

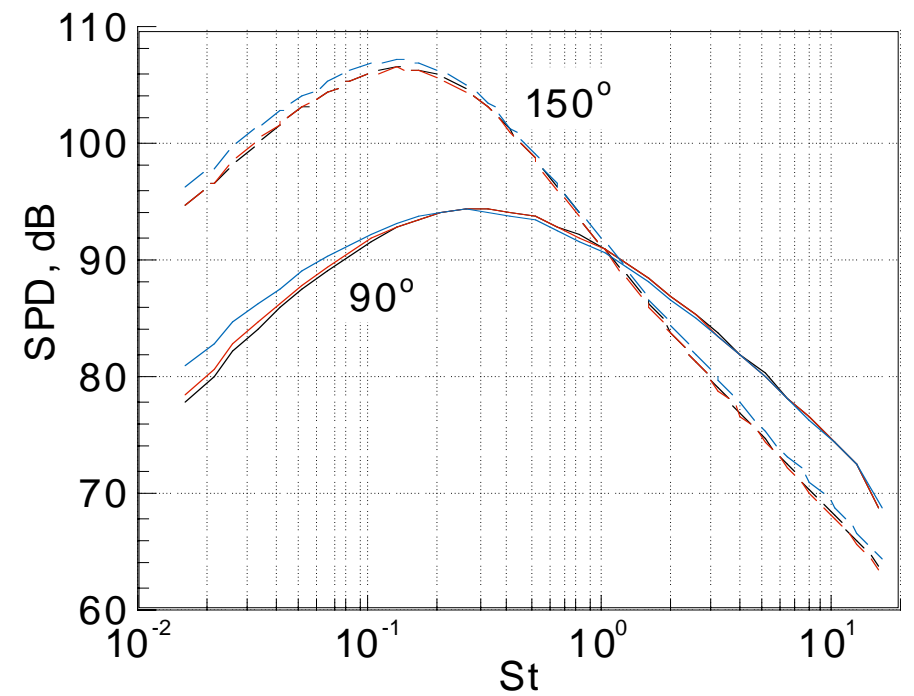

Figure 8 Effect of a particular turbulence model on predicted spectral density of Ma=0.9, cold jet: Chien k-E model (red); SST model (Blue); variable diffusion model (dark). 

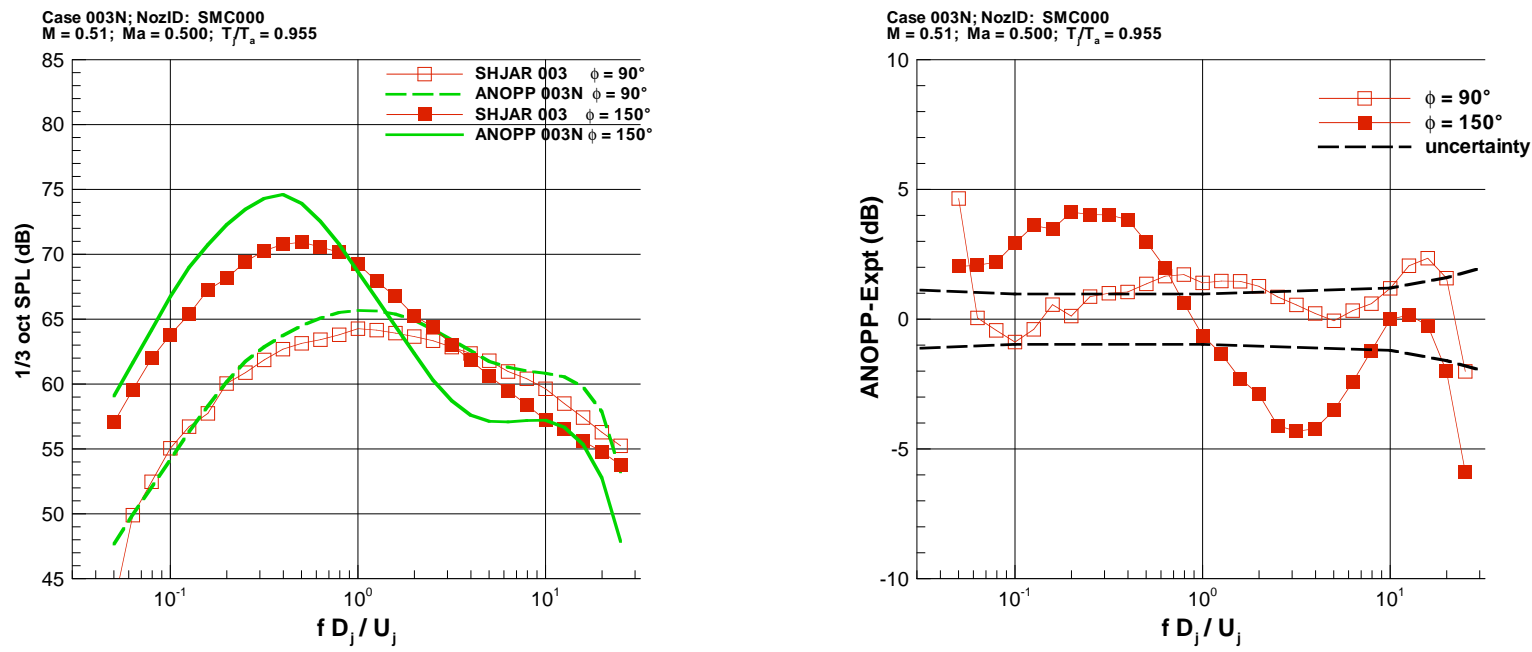

Figure 9 Comparison of ANOPP prediction of axisymmetric Ma $=0.5$ cold jet with experimental data$1 / 3$ octave band SPL at $90^{\circ}$ and $150^{\circ}$. Spectra transformed to 100Dj radius, with no atmospheric attenuation (left); Difference between prediction and data with experimental uncertainty bands (right).
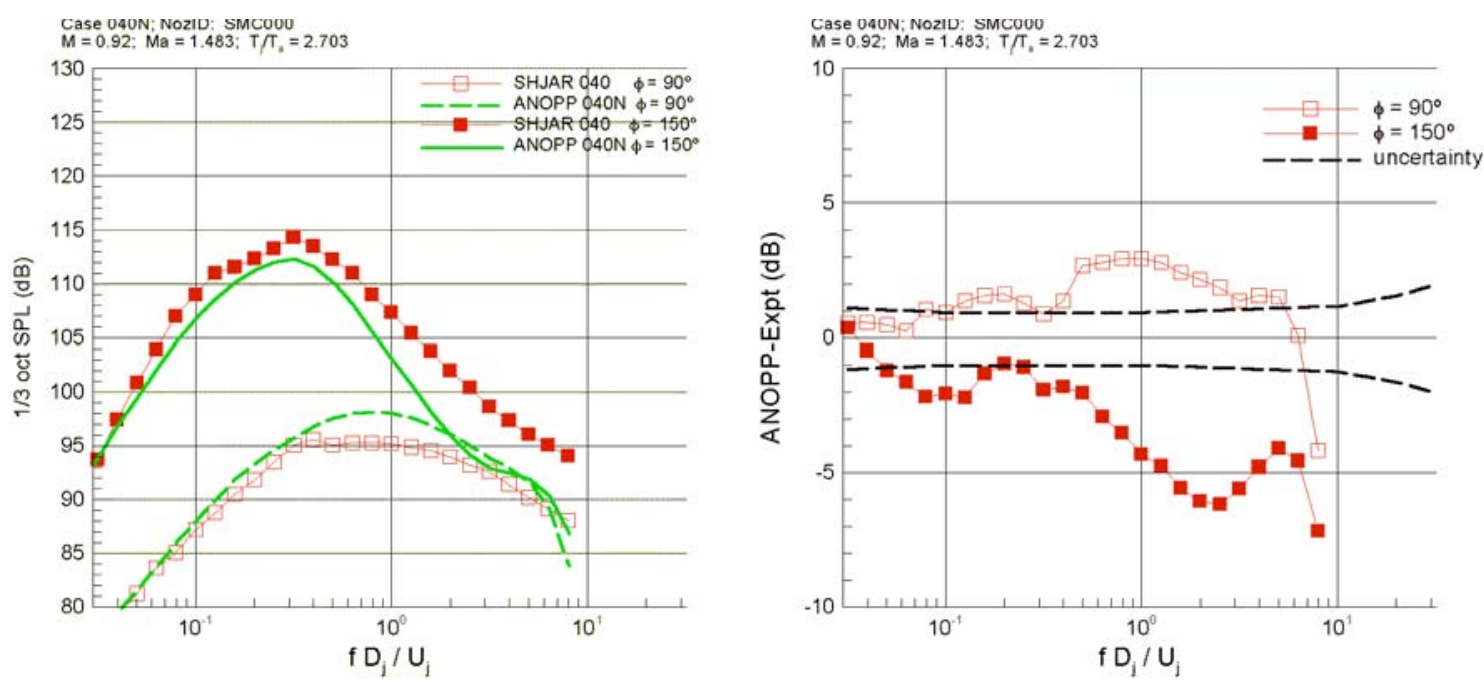

Figure 10 Same as Figure 9 but for axisymmetric $M a=0.9$, hot jet $\left(T_{s, j} / T_{\infty}=2.7\right)$.
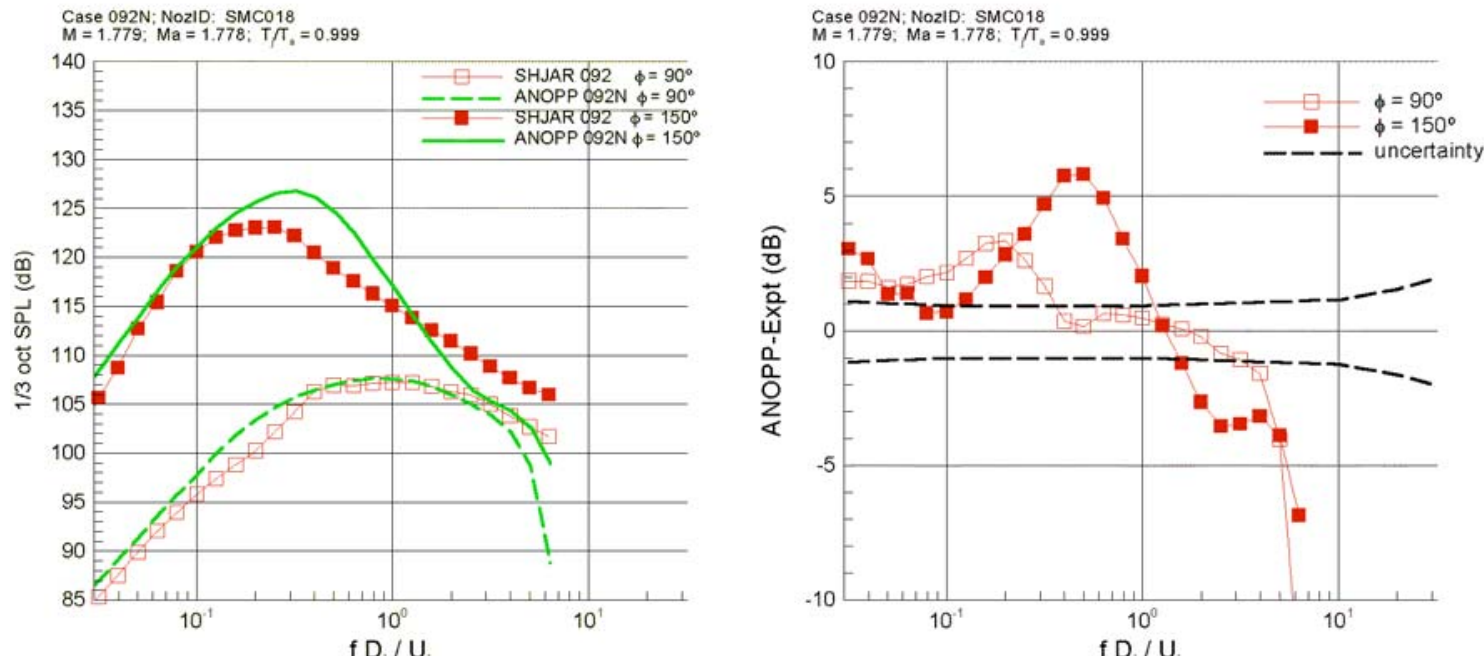

Figure 11 Same as Figure 9 but for axisymmetric ideally expanded nozzle with $M=1.8$, isothermal jet $\left(T_{s, j} / T_{\infty}=1.0\right)$.

NASA/TM-2008-215275 

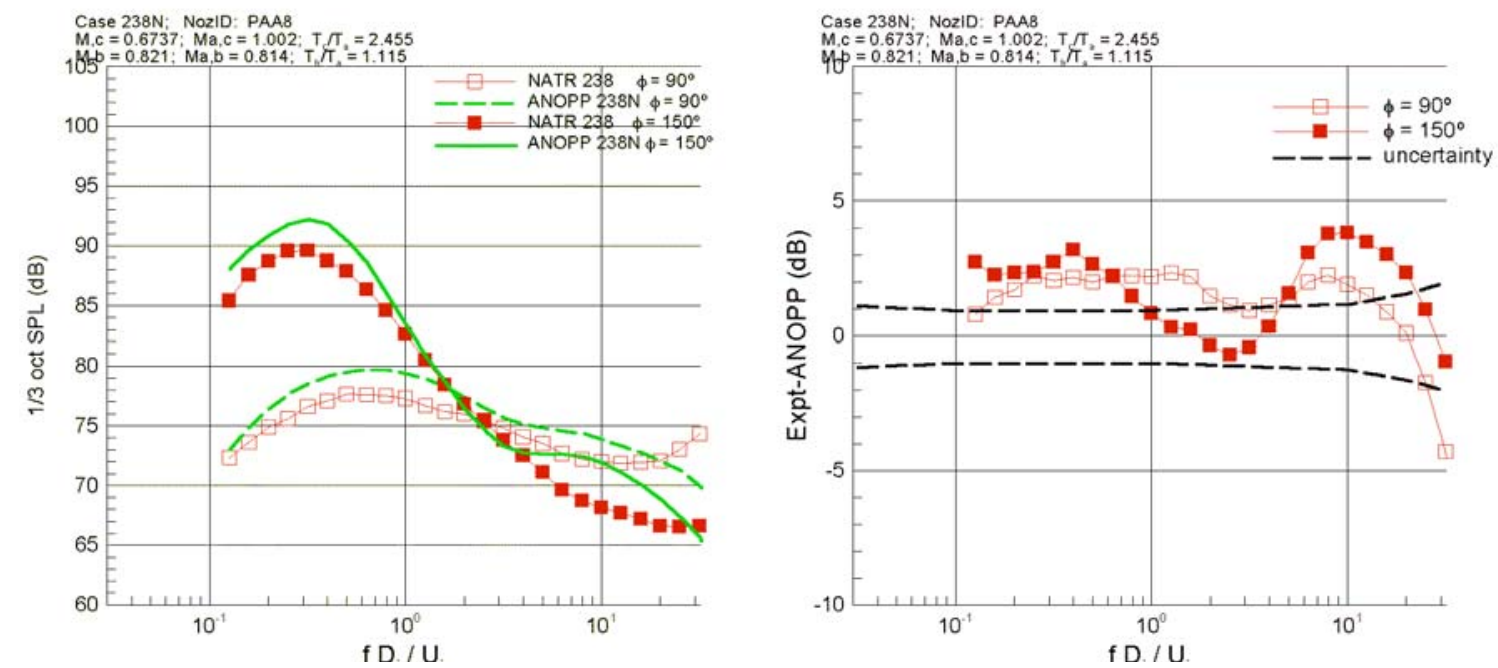

Figure 12 Same as Figure 9 but for separate flow nozzle with $M a=1.0, T_{j, s} / T_{\infty}=2.46$ core flow and $M a=0.82, T_{j, s} / T_{\infty}=1.12$ fan flow.
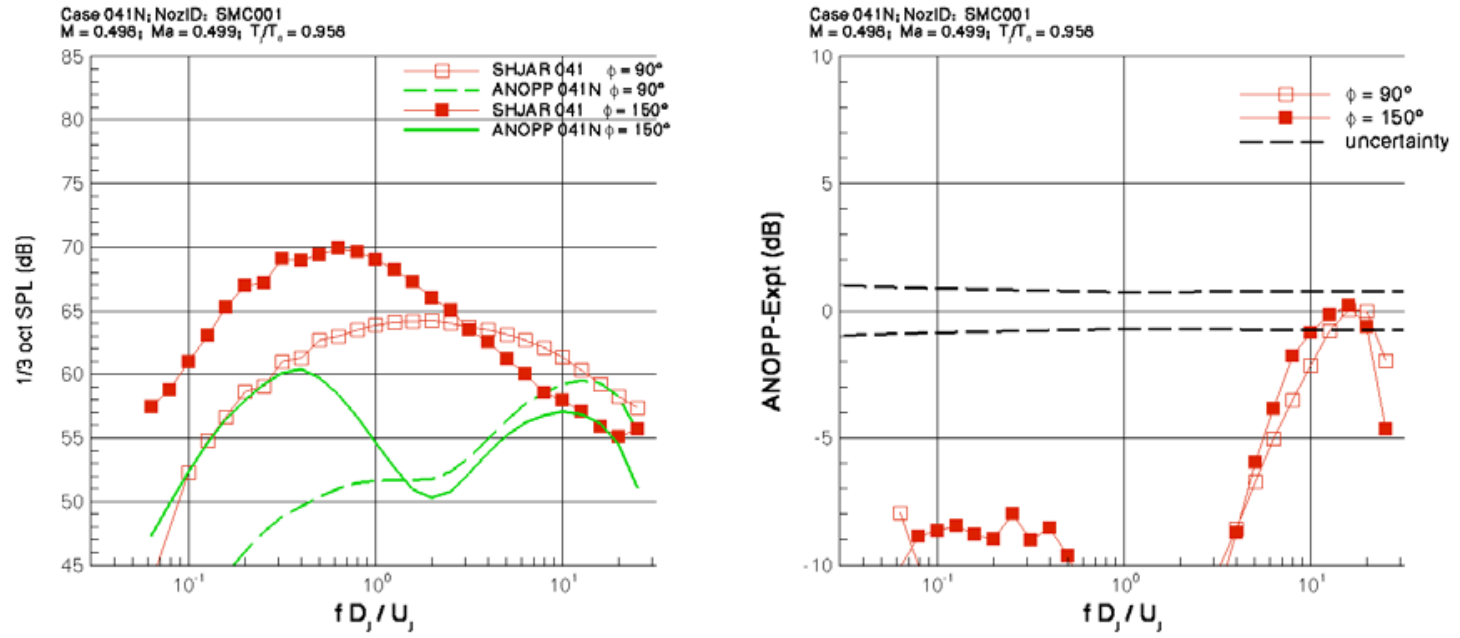

Figure 13 Same as Figure 9 but for nozzle with six chevrons with $5^{\circ}$ penetrations.

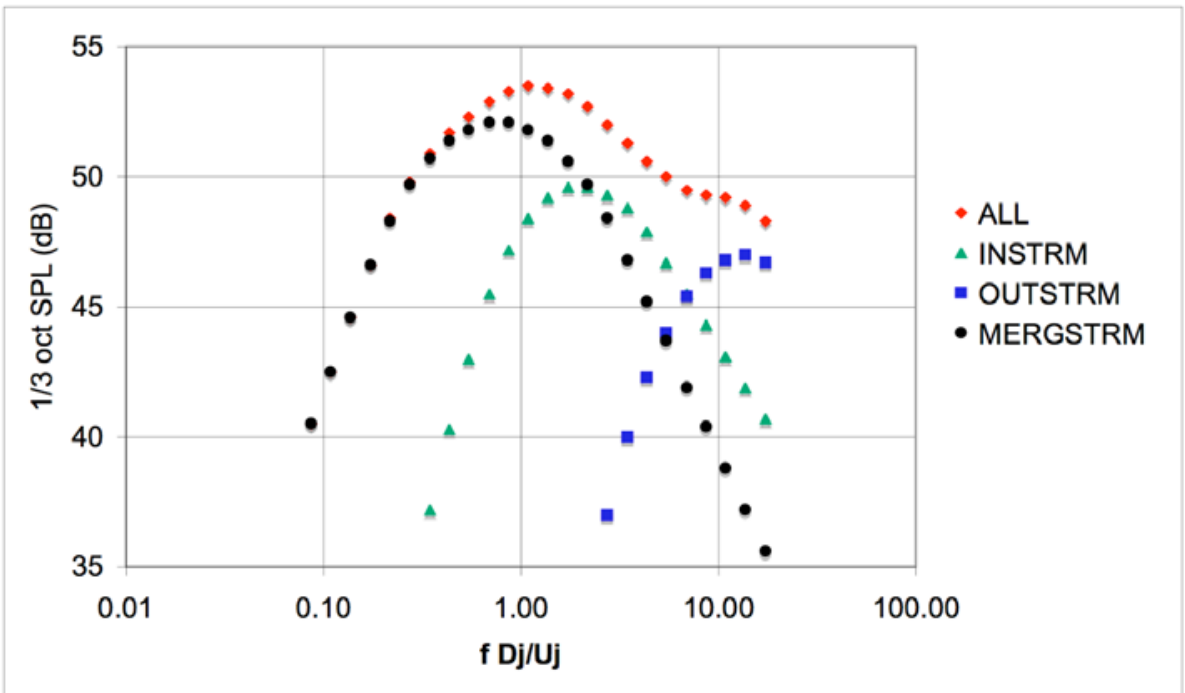

Figure 14 ANOPP source component breakdown for Ma=0.5 cold jet at $90^{\circ}$ to jet axis. 

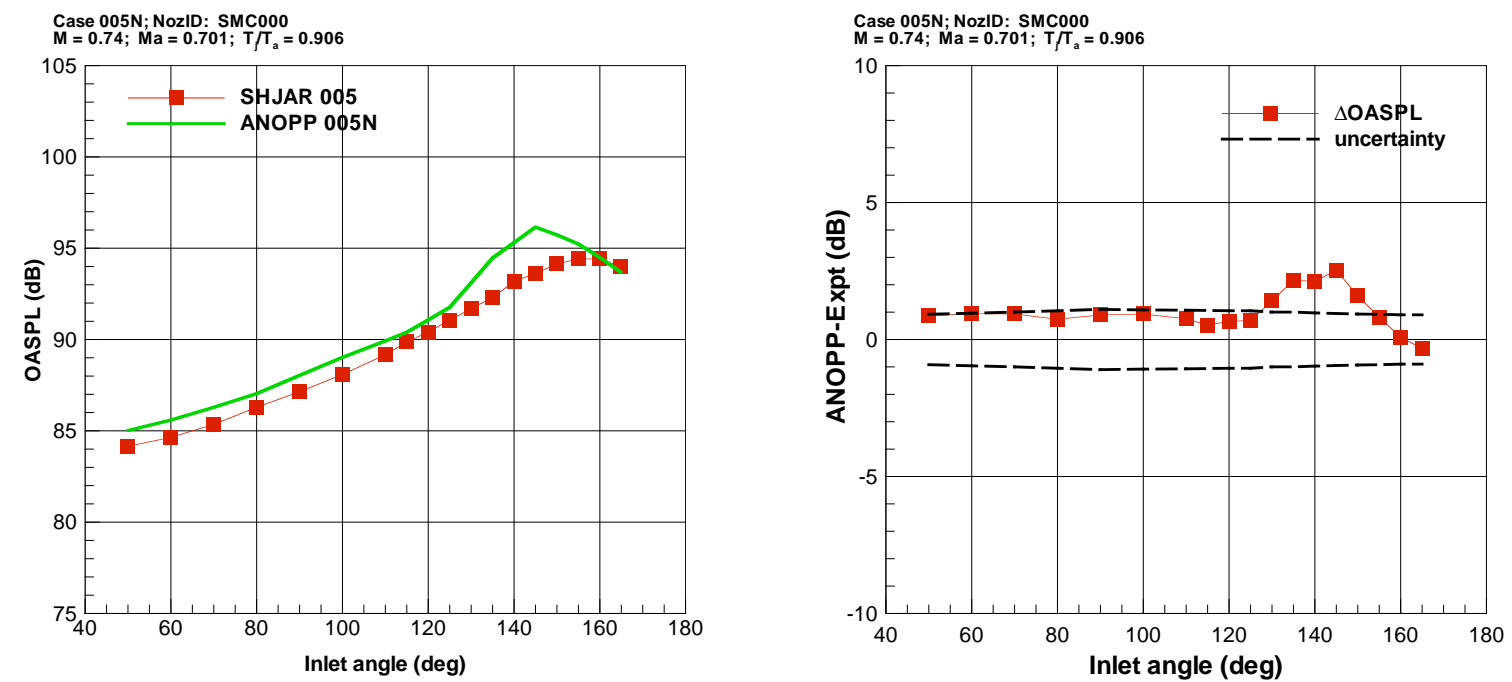

Figure 15 Comparison of ANOPP Prediction of single-stream Ma=0.5 cold jet-OASPL vs polar angle from upstream axis. Data transformed to 100Dj radius, with no atmospheric attenuation (right); Difference between prediction and data with experimental uncertainty band (left).

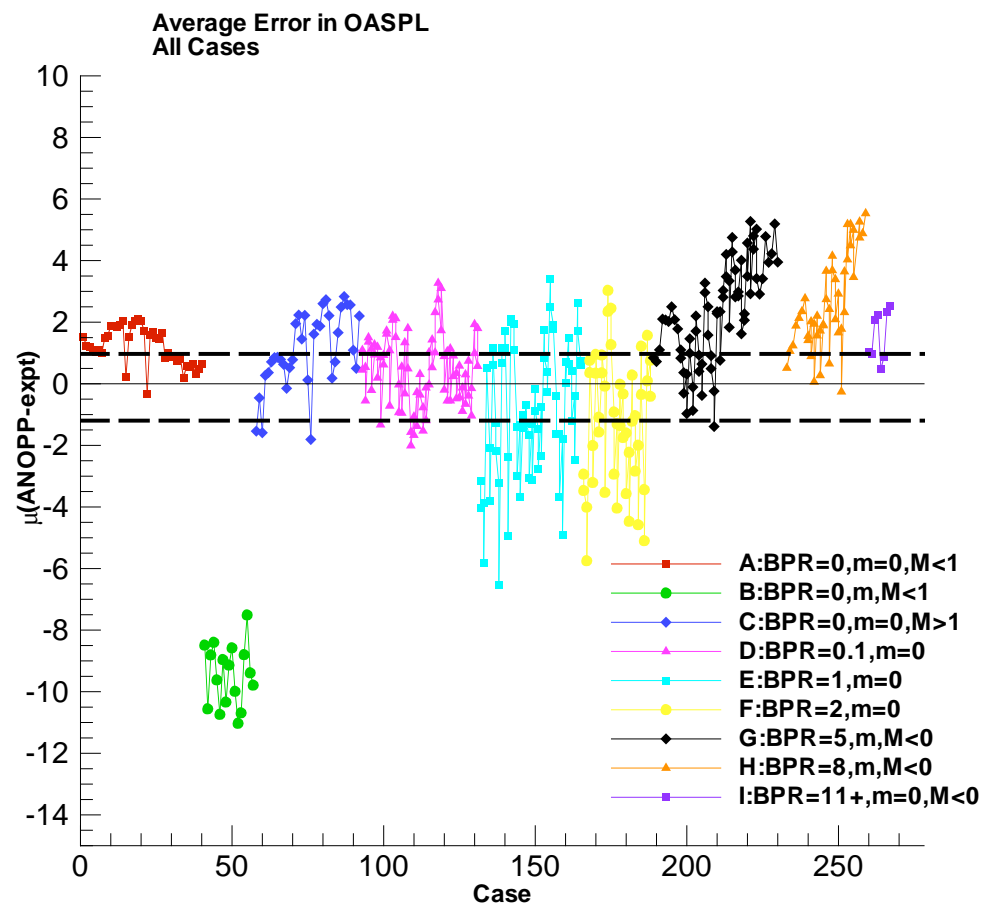

Figure 16 Average error in OASPL across all angles $50^{\circ}-165^{\circ}$ for all jet cases assessed, along with experimental uncertainty bars. 


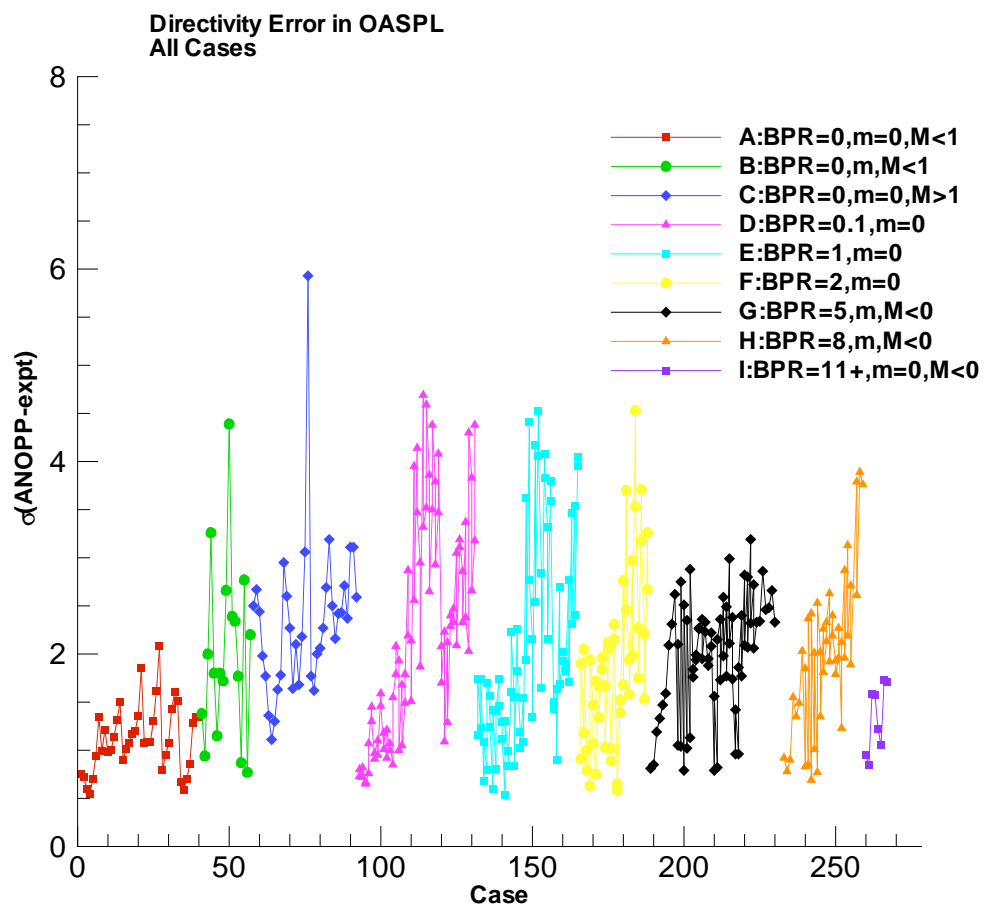

Figure 17 RMS of error in OASPL across all angles $50^{\circ}-165^{\circ}$ for all jet cases assessed, along with experimental uncertainty bars

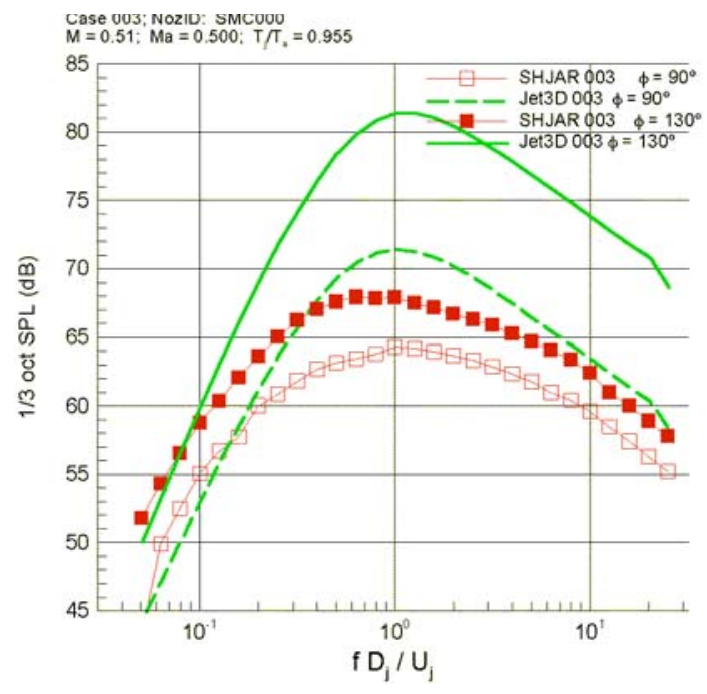

Figure 18 Comparison of Jet $3 D$ prediction of Ma=0.5 cold jet-1/3 octave band $S P L$ at $90^{\circ}$ and $130^{\circ}$. 


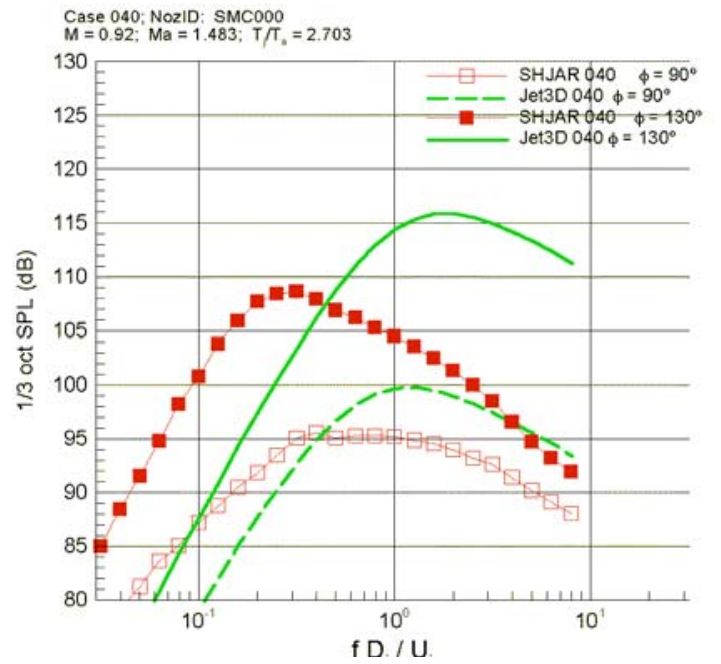

Figure 19 Comparison of Jet3D prediction of $M a=0.9$, hot jet $\left(T_{j, s} / T_{\infty}=2.7\right)$ with experimental data$1 / 3$ octave band $S P L$ at $90^{\circ}$ and $130^{\circ}$.

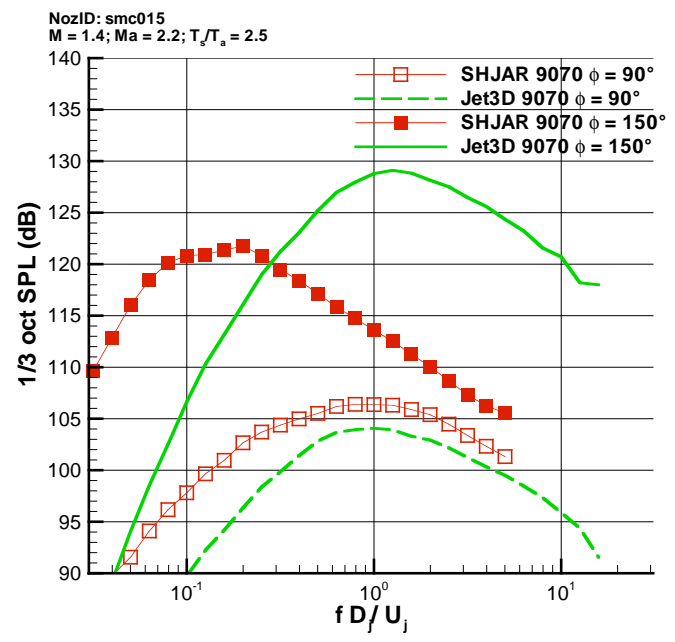

Figure 20 Comparison of Jet $3 D$ prediction of $M=1.4$ hot jet (Yamamoto single-stream jet)

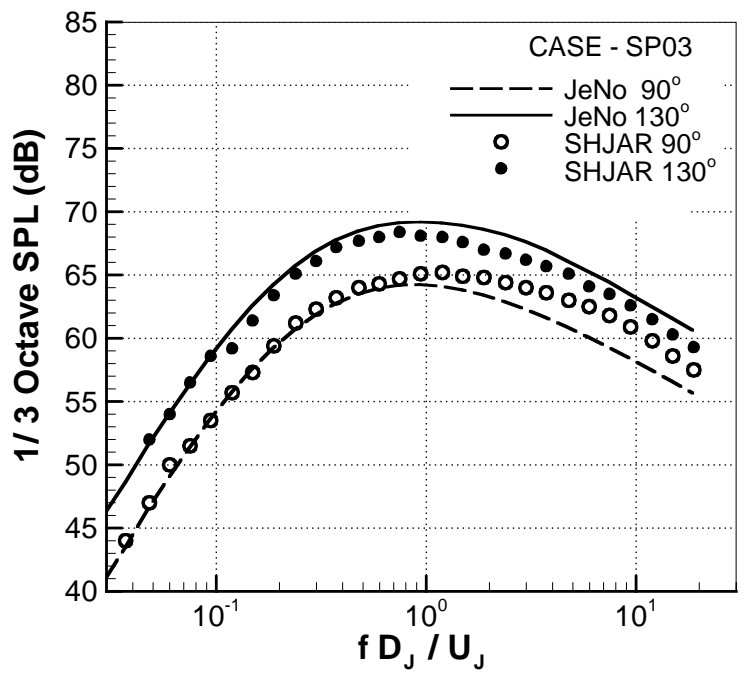

Figure 21 Comparison of JeNo prediction of Ma=0.5 cold jet with experimental data-1/3 octave band SPL at $90^{\circ}$ and $130^{\circ}$. 


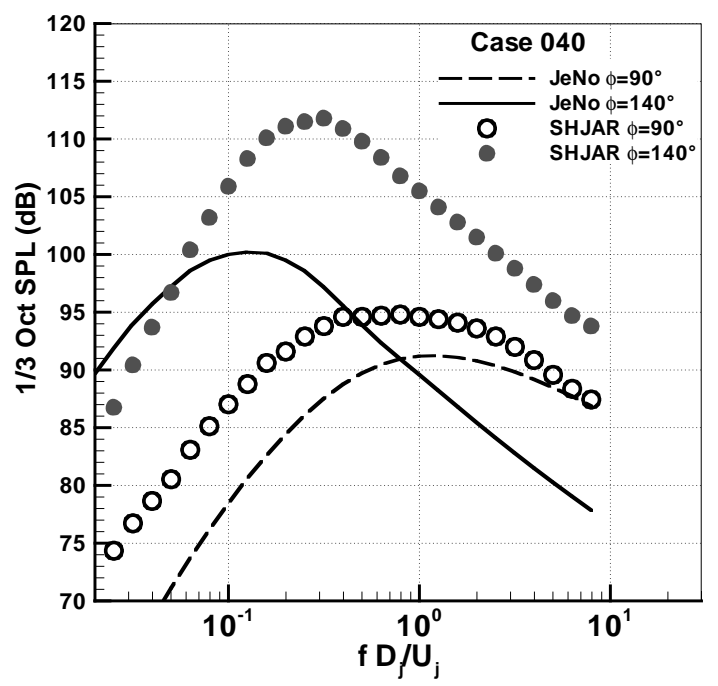

Figure 22 Comparison of JeNo prediction of $M a=0.9$, hot jet $\left(T_{j, s} / T_{\infty}=2.7\right)$ with experimental data-1/3 octave band SPL at $90^{\circ}$ and $140^{\circ}$.

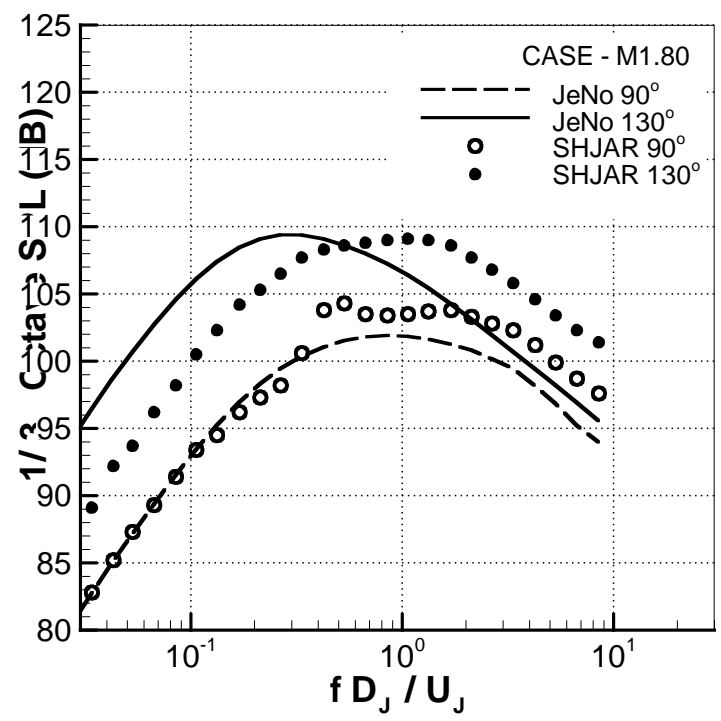

Figure 23 Comparison of JeNo prediction of $M=1.8$ cold jet with experimental data-1/3 octave band SPL at $90^{\circ}$ and $130^{\circ}$. 

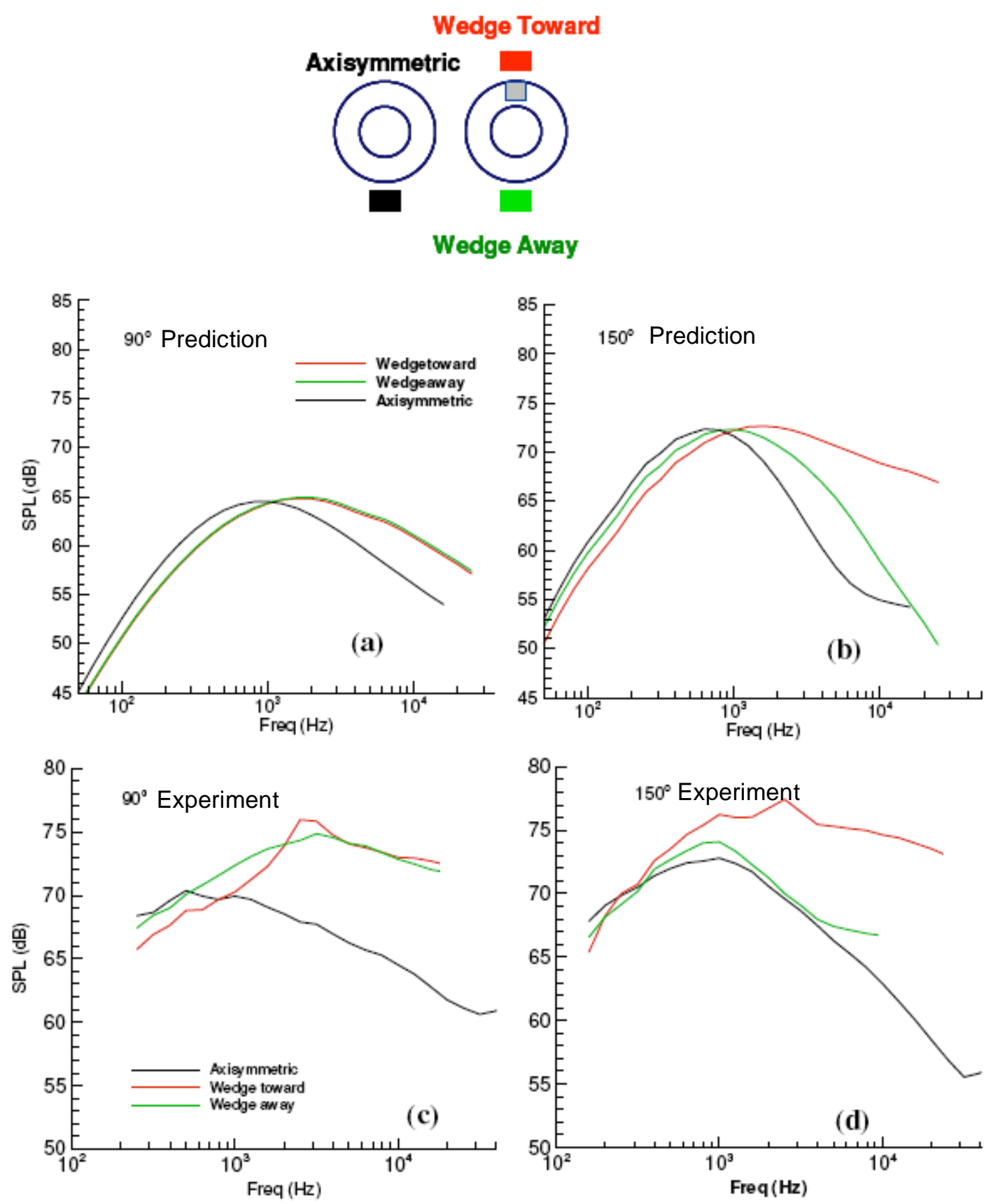

Figure 24 Lossless third-octave spectral density for an offset Fan-Wedge concept and comparisons with the base 5BB geometry at indicated inlet angles on a 80.24-ft arc: (a) and (b) predictions with the line-of-sight method; (c) and (d) NATR data.

\section{References}

1 Farassat, F., Doty, M.J., and Hunter, C.A. "The acoustic analogy - a powerful tool in aeroacoustics with emphasis on jet noise prediction". AIAA Paper 2004-2872, (2004).

2 Hunter, C.A. An Approximate Jet Noise Prediction Method based on Reynolds-Averaged Navier-Stokes Computational Fluid Dynamics Simulation. D.Sc. Dissertation, The George Washington University, January 2002. 
3 Davies, P.O.A.L., Fisher, M.J., and Barrat, M.J. "The Characteristics of the Turbulence in the Mixing Region of a Round Jet". J Fluid Mech, 15, , 337-367 (1963).

4 Khavaran, A. "Noise generation in hot jets," NASA CR-2007-214924 (2007).

5 Viswanathan. K. "Jet aeroacoustic testing: issues and implications," AIAAJ 41, 1674-1689.

6 Ahuja. K.K., "Designing clean jet-noise facilities and making accurate jet-noise measurements," Intl J. Aeroacoustics 2, 314-412 (2003).

7 Bridges, J. \& Brown, C.A., "Validation of the Small Hot Jet Acoustic Rig for Jet Noise Research," AIAA Paper 2005-2846, May 2005.

8 Lee, S.S, \& Bridges, J., "Phased array study of dual-flow jet noise: effect of nozzles and mixers," AIAA Paper 2006-2647 (2006).

9 Bridges, J. \& Wernet, M.P. "Measurements of the aeroacoustic sound source in hot jets," AIAA Paper 2003-3130 (2003).

10 Bridges, J., and Wernet, M.P., "Cross-Stream PIV Measurements of Jets with Internal Lobed Mixers," AIAA Paper 2004-2896, 2004

11 Bridges, J., "Effect of heat on space-time correlations in jets," AIAA Paper 2006-2534 (2006).

12 Viswanathan, K. \& Clark, L.T., "Effect of nozzle internal contour on jet aeroacoustics," Intl J Aeroacoustics 3, 103-135 (2004).

13 Viswanathan, K., “Aeroacoustics of hot jets.” J Fluid Mech 516 39-82 (2004).

14 Tanna, H.K., P.D. Dean, R.H. Burrin, "The generation and radiation of supersonic jet noise, part III, Turbulent mixing noise data," AFAPL-TR-76-65, 1976.

15 Georgiadis, N. J., Yoder, D. A., and Engblom, W. A., "Evaluation of modified two-equation turbulence models for jet flow predictions," AIAAJ, 44(12), (2006), pp. 3107-3114. 


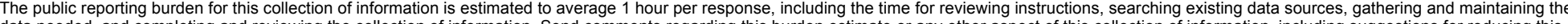

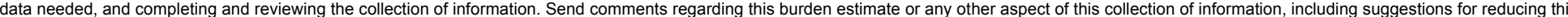

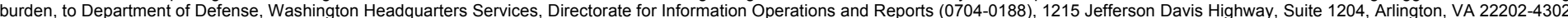

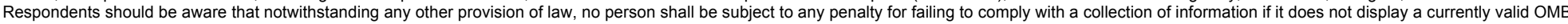
control number.

PLEASE DO NOT RETURN YOUR FORM TO THE ABOVE ADDRESS.

\section{REPORT DATE (DD-MM-YYYY) \\ 2. REPORT TYPE \\ 3. DATES COVERED (From - To)}

01-09-2008

\section{TITLE AND SUBTITLE}

Technical Memorandum

Assessment of Current Jet Noise Prediction Capabilities

5a. CONTRACT NUMBER

5b. GRANT NUMBER

5c. PROGRAM ELEMENT NUMBER

\section{AUTHOR(S)}

Bridges, James, E.; Khavaran, Abbas; Hunter, Craig, A.

\section{5d. PROJECT NUMBER}

5e. TASK NUMBER

5f. WORK UNIT NUMBER

WBS 984754.02.07.03.17.02

\section{PERFORMING ORGANIZATION} REPORT NUMBER

E-16545

National Aeronautics and Space Administration

John H. Glenn Research Center at Lewis Field

Cleveland, Ohio 44135-3191

\section{SPONSORING/MONITORING AGENCY NAME(S) AND ADDRESS(ES)}

National Aeronautics and Space Administration

Washington, DC 20546-0001

10. SPONSORING/MONITORS
ACRONYM(S)
NASA
11. SPONSORING/MONITORING
REPORT NUMBER
NASA/TM-2008-215275

\section{DISTRIBUTION/AVAILABILITY STATEMENT}

Unclassified-Unlimited

Subject Categories: 7 and 34

Available electronically at http://gltrs.grc.nasa.gov

This publication is available from the NASA Center for AeroSpace Information, 301-621-0390

\section{SUPPLEMENTARY NOTES}

\section{ABSTRACT}

An assessment was made of the capability of jet noise prediction codes over a broad range of jet flows, with the objective of quantifying current capabilities and identifying areas requiring future research investment. Three separate codes in NASA's possession, representative of two classes of jet noise prediction codes, were evaluated, one empirical and two statistical. The empirical code is the Stone Jet Noise Module (ST2JET) contained within the ANOPP aircraft noise prediction code. It is well documented, and represents the state of the art in semi-empirical acoustic prediction codes where virtual sources are attributed to various aspects of noise generation in each jet. These sources, in combination, predict the spectral directivity of a jet plume. A total of 258 jet noise cases were examined on the ST2JET code, each run requiring only fractions of a second to complete. Two statistical jet noise prediction codes were also evaluated, JeNo v1, and Jet3D. Fewer cases were run for the statistical prediction methods because they require substantially more resources, typically a Reynolds-Averaged Navier-Stokes solution of the jet, volume integration of the source statistical models over the entire plume, and a numerical solution of the governing propagation equation within the jet. In the evaluation process, substantial justification of experimental datasets used in the evaluations was made. In the end, none of the current codes can predict jet noise within experimental uncertainty. The empirical code came within $2 \mathrm{~dB}$ on a $1 / 3$ octave spectral basis for a wide range of flows. The statistical code Jet3D was within experimental uncertainty at broadside angles for hot supersonic jets, but errors in peak frequency and amplitude put it out of experimental uncertainty at cooler, lower speed conditions. Jet3D did not predict changes in directivity in the downstream angles. The statistical code JeNo,v1 was within experimental uncertainty predicting noise from cold subsonic jets at all angles, but did not predict changes with heating of the jet and did not account for directivity changes at supersonic conditions. Shortcomings addressed here give direction for future work relevant to the statistical-based prediction methods. A full report will be released as a chapter in a NASA publication assessing the state of the art in aircraft noise prediction.

\section{SUBJECT TERMS}

Jet flow; Turbulence; Correlation; Jet aircraft noise; Particle image velocimetry; Velocity distribution; Prediction analysis techniques; Navier-Stokes equation; Laser anemometers; Velocity measurements; High resolution; Temperature effects

\begin{tabular}{|c|c|c|c|}
\hline 16. SECURIT & ASSIFICATION & & 17. LIMITATION OF \\
\hline $\begin{array}{l}\text { a. REPORT } \\
\text { U }\end{array}$ & $\begin{array}{l}\text { b. ABSTRACT } \\
U\end{array}$ & $\begin{array}{l}\text { c. THIS } \\
\text { PAGE } \\
\text { U }\end{array}$ & UU \\
\hline
\end{tabular}

18. NUMBER
OF
PAGES
28
19a. NAME OF RESPONSIBLE PERSON STI Help Desk (email:help@sti.nasa.gov) 19b. TELEPHONE NUMBER (include area code) 301-621-0390



